\title{
Membrane-anchored uPAR regulates the proliferation, marrow pool size, engraftment, and mobilization of mouse hematopoietic stem/progenitor cells
}

\author{
Marc Tjwa, ${ }^{1}$ Nicolai Sidenius, ${ }^{2}$ Rute Moura, ${ }^{1}$ Sandra Jansen, ${ }^{1}$ Koen Theunissen, ${ }^{3}$ \\ Annapaola Andolfo, ${ }^{2}$ Maria De Mol, ${ }^{1}$ Mieke Dewerchin, ${ }^{1}$ Lieve Moons, ${ }^{1}$ Francesco Blasi, ${ }^{2}$ \\ Catherine Verfaillie, ${ }^{4}$ and Peter Carmeliet ${ }^{1}$ \\ ${ }^{1}$ VIB — Vesalius Research Center, Katholieke Universiteit Leuven, Leuven, Belgium. ${ }^{2}$ San Raffaele Scientific Institute and the IFOM Foundation, \\ FIRC Institute of Molecular Oncology, Milan, Italy. ${ }^{3}$ Department of Hematology, University Hospital Gasthuisberg, Leuven, Belgium. \\ ${ }^{4}$ Stem Cell Institute, Katholieke Universiteit Leuven, Leuven, Belgium.
}

\begin{abstract}
The mechanisms of BM hematopoietic stem/progenitor cell (HSPC) adhesion, engraftment, and mobilization remain incompletely identified. Here, using WT and transgenic mice, we have shown that membrane-anchored plasminogen activator, urokinase receptor ( ${ }^{\mathrm{uPAR}}$ ) marks a subset of HSPCs and promotes the preservation of the size of this pool of cells in the BM. Loss or inhibition of ${ }^{M} \mathrm{UPAR}$ increased HSPC proliferation and impaired their homing, engraftment, and adhesion to the $\mathrm{BM}$ microenvironment. During mobilization, ${ }^{M} \mathrm{uPAR}$ was inactivated by plasmin via proteolytic cleavage. Cell-autonomous loss of the gene encoding ${ }^{\mathrm{M}} \mathrm{uPAR}$ also impaired long-term engraftment and multilineage repopulation in primary and secondary recipient mice. These findings identify ${ }^{\mathrm{M}} \mathrm{uPAR}$ and plasmin as regulators of the proliferation, marrow pool size, homing, engraftment, and mobilization of HSPCs and possibly also of HSCs.
\end{abstract}

\section{Introduction}

Hematopoietic stem/progenitor cells (HSPCs) refer to a heterogenous population of HSCs and slightly more committed hematopoietic progenitor cells (HPCs). BM HSPCs express various cell surface receptors, such as Sca-1, cKit, CD34, CD150, and CD201, that regulate HSPC marrow pool size, adhesion, homing, engraftment, and/or mobilization (1-11). The plasminogen activator, urokinase receptor (uPAR) is related to the HSPC marker Sca-1 (8). Membrane-anchored uPAR ( ${ }^{\mathrm{M}} \mathrm{uPAR}$ ) consists of 3 domains $\left(\mathrm{D}_{\mathrm{I}} \mathrm{D}_{\mathrm{II}} \mathrm{D}_{\mathrm{III}}\right)$ and a glycosyl phosphatidylinositol anchor. ${ }^{\mathrm{M}} \mathrm{uPAR}$ binds plasminogen activator, urokinase (uPA), thereby amplifying pericellular plasmin proteolysis, but it also orchestrates - in a nonproteolytic manner - cellular responses such as migration, adhesion, differentiation, and proliferation (12). ${ }^{\mathrm{M}} \mathrm{uPAR}$, which lacks a cytosolic domain, transmits signals through association with other transmembrane receptors, including integrins and GPCRs, and extracellular molecules, such as vitronectin (12). ${ }^{\mathrm{M}} \mathrm{uPAR}$ can be proteolytically cleaved in the linker region between $\mathrm{D}_{\mathrm{I}}$ and $\mathrm{D}_{\mathrm{II}}$, and at the juxtamembrane domain, thereby releasing the soluble uPAR ( ${ }^{\mathrm{u}} \mathrm{uPAR}$ ) fragments $\mathrm{D}_{\text {II }} \mathrm{D}_{\text {III }}$ and $\mathrm{D}_{\mathrm{I}} \mathrm{D}_{\text {II }} \mathrm{D}_{\text {III }}$, respectively $(13-16)$. Recombinant $\mathrm{D}_{\text {II }} \mathrm{D}_{\text {III }}$ affects chemotaxis and adhesion of certain cell types in vitro $(15,17,18)$.

So far, it remains unknown whether ${ }^{\mathrm{M}} \mathrm{uPAR}$ has any role in regulating the homing or mobilization of HSPCs, or their adhesion to

Conflict of interest: The authors have declared that no conflict of interest exists. Nonstandard abbreviations used: BMC, BM cell; BMMC, BM mononuclear cell; CFU-C, cell-derived CFU; CFU-S, spleen-derived CFU; CRU, competitive repopulation unit; FACS, fluorescence-activated cell sorting; 5-FU, 5-fluorouracil; HPC, hematopoietic progenitor cell; HSPC, hematopoietic stem/progenitor cell; ${ }^{\mathrm{M}} \mathrm{UPAR}$, membraneanchored uPAR; ${ }^{\mathrm{uPAR}}$, soluble UPAR; sVCAM-1, soluble VCAM-1; uPA, plasminogen activator, urokinase; uPAR, uPA receptor.

Citation for this article: J. Clin. Invest. 119:1008-1018 (2009). doi:10.1172/JCI36010. the BM microenvironment. A few recent studies documented that administration of a synthetic human uPAR peptide, as surrogate for $\mathrm{D}_{\mathrm{II}} \mathrm{D}_{\mathrm{III}}$, increases chemotaxis of CD34 $4^{+}$cells in vitro (19) and the number of circulating CD34+ cells in vivo (20). However, the role of endogenous ${ }^{\mathrm{s}} \mathrm{uPAR}$ in $\mathrm{HSPC}$ mobilization remains unclear (21). Moreover, these reports did not analyze a possible role for the endogenous ${ }^{\mathrm{M}} \mathrm{uPAR}$ in HSPC biology. Here, as an initial step to unravel the role of ${ }^{\mathrm{M}} \mathrm{uPAR}$, we focused our attention primarily on hematopoietic progenitors and document what we believe to be a novel role of ${ }^{\mathrm{uPAR}}$ in the preservation of the marrow pool size as well as the regulation of proliferation status, homing, engraftment, and adhesion of HSPCs to the BM microenvironment.

\section{Results}

${ }^{M}$ uPAR is expressed on a subpopulation of HSPCs. To investigate whether $\mathrm{M}_{\mathrm{UPAR}}$ is expressed on HSPCs, we used specific anti-uPAR antibodies and a panel of antibodies in order to immunophenotype various populations of HSPCs. Flow cytometry of cells harvested from the BM of WT mice revealed that ${ }^{\mathrm{M}} \mathrm{UPAR}$ was expressed on about $20 \%$ of HSPCs $\left(16 \% \pm 5 \%\right.$ of Sca- $1^{+}$cells, $21 \% \pm 1 \%$ of Lin-Sca- $1^{+}$cells, $17 \% \pm 1 \%$ of Lin $^{-} \mathrm{cKit}^{+}$cells; Supplemental Figure $1 \mathrm{~A}$; supplemental material available online with this article; doi:10.1172/JCI36010DS1).

${ }^{M}$ UPAR regulates the marrow pool size of HSPCs in the BM. To evaluate the function of ${ }^{\mathrm{M}} \mathrm{uPAR}$ on HSPCs, we analyzed whether loss of ${ }^{\mathrm{M}} \mathrm{uPAR}$ depleted HSPCs from the BM. Immunophenotyping of BM cells (BMCs) revealed that Plaur ${ }^{--}$mice, which are deficient in uPAR, contained over $30 \%$ fewer Sca- $1^{+}$cells, Lin-Sca- $1^{+}$cells, and $\mathrm{Lin}^{-} \mathrm{CKit}^{+}$cells (Figure 1A), and HSPC culture assays also revealed approximately $40 \%$ fewer cell-derived CFUs (CFU-Cs; Supplemental Results and Figure 1B). Despite reduced numbers of HSPCs in the BM of Plaur ${ }^{-1}$ mice, wbc and rbc counts in the peripheral blood 
A

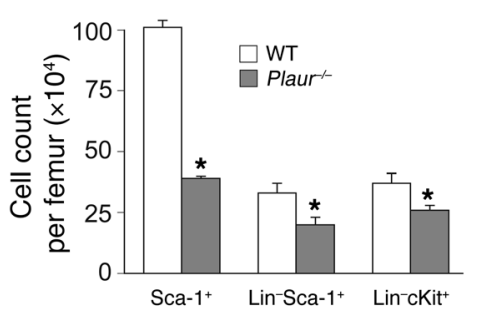

B

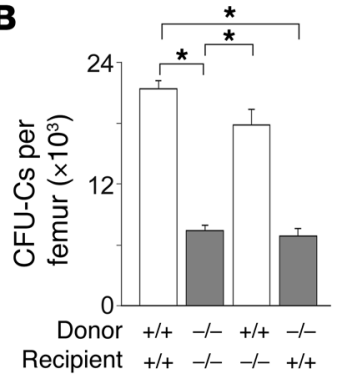

C

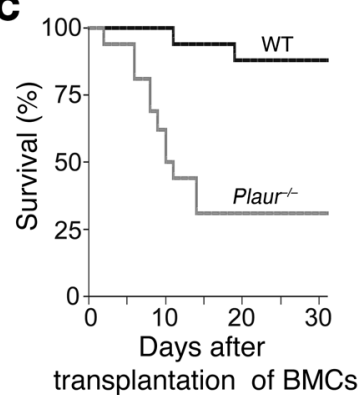

Figure 1

MuPAR marks a subset of HSPCs and preserves their pool size in the BM. (A) Decreased steady-state counts of various HSPC populations in the BM of Plaur ${ }^{-1}$ compared with WT mice. ${ }^{*} P<0.05$ versus WT $(n=4-9)$. (B) WT and Plaur-1- mice were transplanted with syngeneic WT or Plaur-1- BMCs after lethal irradiation. At 6 weeks after transplantation, peripheral blood counts in the recipient mice were fully normalized (not shown). Counting of the number of CFU-Cs in the BM revealed that the number of HSPCs was reduced in the BM of mice grafted with Plaur ${ }^{-1}$ BM. Consistent herewith, fewer CFU-Cs were detected in nontransplanted Plaur ${ }^{-1}$ mice (not shown). ${ }^{*} P<0.05(n=4)$. (C) Fewer lethally irradiated splenectomized WT mice survived when transplanted with $1 \times 10^{5}$ Plaur ${ }^{-1}$ BMCs compared with WT BMC transplantation. $P<0.05$ versus WT, Cox regression analysis $(n=17)$.

were normal in steady-state conditions (Supplemental Table 1). The restoration of CFU-C depletion by transplantation of WT donor BM in Plaur $/$ - recipients (Figure 1B) suggests that ${ }^{\mathrm{M}} \mathrm{uPAR}$ regulates, as a cell-autonomous factor on HSPCs, the marrow pool size of these progenitors. As Plaur ${ }^{-1}$ mice contained normal numbers of CFU-Cs in the peripheral blood and spleen (Supplemental Results), the absence of ${ }^{\mathrm{M}} \mathrm{uPAR}$ did not simply result in translocation of HSPCs from the BM to the peripheral blood, but caused the depletion of a subset of HSPCs, similar to what occurs when cKit is absent or its function is inhibited (1-3).

Additional evidence for partial depletion of HSPCs in Plaur $/-$ mice was provided by transplanting splenectomized WT mice subjected to lethal irradiation $(9.5 \mathrm{~Gy})$ with $1 \times 10^{5}$ Plaur $^{-1}$ or WT BMCs. Compared with recipients of WT donor cells, fewer Plaur $^{\text {/ }}$ donor cell recipients survived during the initial 2 weeks (Figure 1C). In addition, hematopoiesis at 8 weeks after grafting a mixture of WT and Plaur $1-$ BMCs was derived mainly from WT BMCs (Supplemental Figure 1B). Taken together, these results suggest that the reduced survival of recipients transplanted with Plaur ${ }^{-}$BMCs is caused, at least in part, by the partial depletion of HSPCs; however, as discussed below, it may also be the result of impaired engraftment of these cells.

$M_{u}$ PAR reduces proliferation and apoptosis of HSPCs. The partial depletion of HSPCs in the Plaur $/-$ BM might result from increased death and/or premature differentiation of HSPCs; as adhesion to the BM microenvironment is a prerequisite for reducing aberrant HSPC proliferation $(22,23)$, this would suggest a role for ${ }^{\mathrm{M}} \mathrm{uPAR}$ in retaining HSPCs in the BM microenvironment. Double immunostaining showed that $\mathrm{cKit}^{+}$BMCs coexpressing ${ }^{\mathrm{M}} \mathrm{uPAR}$ primarily resided along the endosteal bone surface (data not shown).

We determined the cell cycle status (by propidium iodide and Pyronin Y staining), apoptosis (TUNEL staining), and proliferation (BrdU labeling) of ${ }^{\mathrm{M}} \mathrm{uPAR}^{+}$and ${ }^{\mathrm{M}} \mathrm{uPAR}^{-} \mathrm{Lin}^{-} \mathrm{cKit}^{+} \mathrm{HSPCs}$ in the $\mathrm{BM}$ of WT mice. Compared with ${ }^{\mathrm{M}} \mathrm{UPAR}^{-}$cells, a larger fraction of ${ }^{\mathrm{uPAR}}{ }^{+}$HSPCs was in the $\mathrm{G}_{\mathrm{o}} / \mathrm{G}_{1}$ phase of the cell cycle (Figure 2 , A-D), while fewer ${ }^{\mathrm{M}} \mathrm{uPAR}^{+}$cells proliferated or were apoptotic (Figure 2, E and F). We also compared the cell cycle status of Lin $^{-} \mathrm{CKit}^{+}$HSPCs in Plaur/- mice: compared with WT mice, fewer
$M_{u}$ PAR promotes homing and engraftment of HSPCs in the BM. To evaluate the role of ${ }^{\mathrm{uPAR}}$ in homing and early engraftment of HSPCs to the $\mathrm{BM}$, we transplanted $5 \times 10^{6} \mathrm{GFP}^{+} \mathrm{BMCs}$ from syngeneic mice ubiquitously expressing GFP (Actb:GFP mice) that were preincubated with either a neutralizing anti- ${ }^{\mathrm{M}} \mathrm{uPAR}$ or a control antibody into lethally irradiated recipient WT mice. Plaur ${ }^{\prime-}$ BMCs were not used, as they are depleted of $\mathrm{MuPAR}^{+}$HSPCs. Compared with control IgG, anti- ${ }^{\mathrm{M}} \mathrm{uPAR}$ impaired the homing and early engraftment of $\mathrm{GFP}^{+}$cells specifically to the $\mathrm{BM}$ (Figure $3 \mathrm{~A}$ ). That ${ }^{\mathrm{M}} \mathrm{uPAR}$ regulates HSPC homing and early engraftment was further confirmed by the finding that preincubation with anti- ${ }^{\mathrm{M}} \mathrm{uPAR}$ reduced the homing and early engraftment of a HSPC-enriched population of WT Ly5.1 $1^{+} \mathrm{Lin}^{-} \mathrm{cKit}^{+}$cells to the BM of lethally irradiated splenectomized WT Ly5.2+ recipients by about 55\% (Figure 3B). The magnitude of these effects was comparable to that induced by inhibition of $\alpha_{4} \beta_{1}$ integrin and other molecules $(24,25)$. In addition, the number of CFU-Cs in the BM after transplantation of WT $\mathrm{Lin}^{-} \mathrm{CKit}^{+} \mathrm{HSPCs}$ preincubated with anti- ${ }^{\mathrm{M}} \mathrm{uPAR}$ was significantly reduced (IgG, $323 \pm 35 \mathrm{CFU}-\mathrm{Cs} / 10^{4} \mathrm{BMCs}$; anti-M $\mathrm{uPAR}$, $181 \pm 19$ CFU-Cs $/ 10^{4}$ BMCs; $\left.n=6 ; P<0.05\right)$. These in vivo results were extended by in vitro adhesion assays showing that preincubation with anti- ${ }^{\mathrm{M}} \mathrm{uPAR}$ reduced the adhesion of WT $\mathrm{Lin}^{-} \mathrm{CKit}^{+}$ HSPCs to BM stromal cells (Figure 3C) or to immobilized VCAM-1 or fibronectin (Figure 3, D and E), 2 matrix ligands known to be involved in the adhesion of HSPCs to stromal cells (26).

To study HSPC engraftment functionally, lethally irradiated splenectomized WT mice were transplanted with $1 \times 10^{5} \mathrm{WT}$ BMCs preincubated with anti- ${ }^{\mathrm{u}} \mathrm{uPAR}$ or control antibody. Fewer ${ }^{\mathrm{M}} \mathrm{uPAR}-\mathrm{blocked}$ recipients survived transplantation compared with control recipients (Figure 3F). In concert with our finding that short-term hematopoietic reconstitution by Plaur $^{1-}$ BMCs in lethally irradiated splenectomized WT mice was also impaired (Figure 1C), these data suggest that ${ }^{\mathrm{M} u P A R}$ promotes homing and early engraftment of HSPCs.

Cleavage of ${ }^{M}$ UPAR during HSPC mobilization by plasmin. We next evaluated whether ${ }^{\mathrm{M}} \mathrm{uPAR}$ regulates mobilization of HSPCs from the BM. During release of HSPCs from the BM microenvironment, adhesive signals, such as mKitL, SDF- $1 \alpha$, and CXCR-4, are pro- 


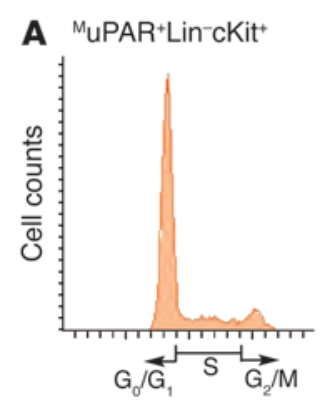

E

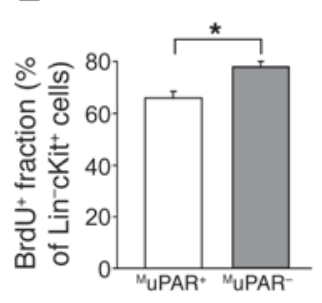

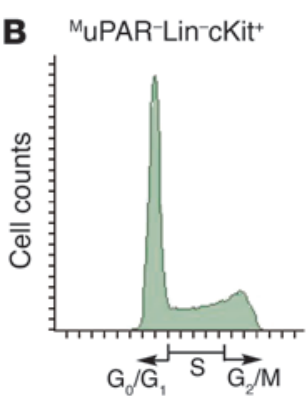

$\mathbf{F}$

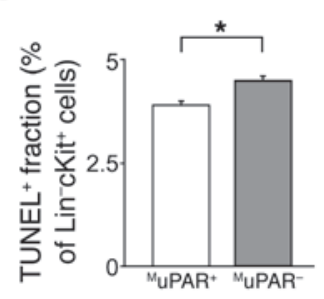

C

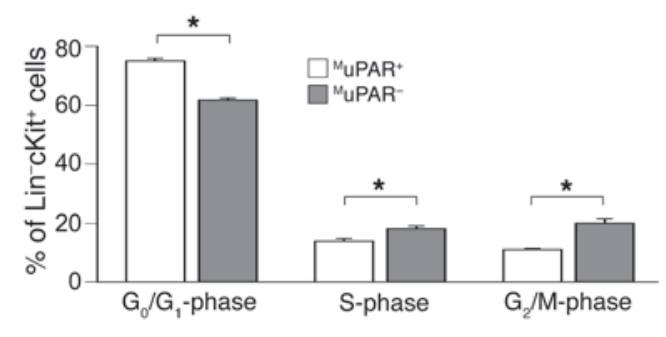

D

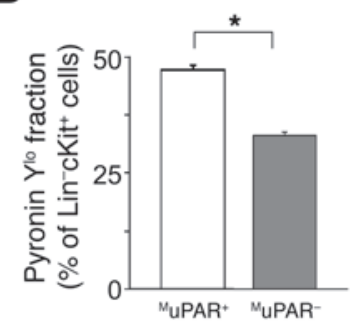

G

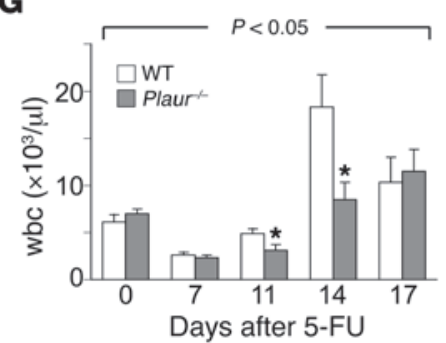

H

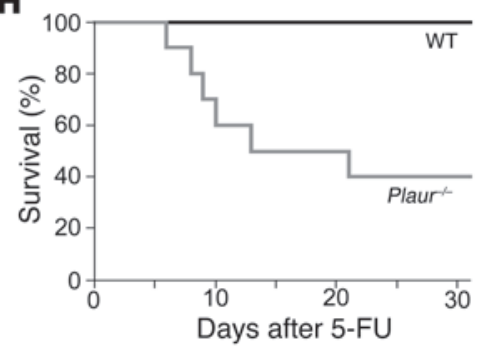

Figure 2

MUPAR promotes HSPC cell-cycle regulation and chemoprotection. (A and B) Representative FACS histogram plots of cell-cycle analysis of $\mathrm{MuPAR}^{+}(\mathbf{A})$ and MuPAR${ }^{-}$(B) Lin-cKit ${ }^{+}$HSPCs in steady-state conditions. (C) Quantitative analysis of the cell-cycle status in Lin-cKit ${ }^{+} \mathrm{HSPC}^{-}$in steady-state conditions. Compared with MuPAR+ HSPCs, fewer HSPCs in the MuPAR- fraction were in $\mathrm{G}_{0} / \mathrm{G}_{1} .{ }^{*} P<0.05(n=4)$. (D-F) Compared with MuPAR+ HSPCs, fewer Lin-cKit ${ }^{+}$HSPCs in the MUPAR ${ }^{-}$fraction were Pyronin Ylo (D), while more cells proliferated (E) or were apoptotic $(\mathbf{F}) .{ }^{*} P<0.05(n=4)$. (G) Hematopoietic recovery in WT and Plaur ${ }^{-1-}$ mice after 5-FU treatment. Compared with WT mice, the wbc counts in Plaur $^{\prime-}$ mice were lower at 7,11 , and 14 days after administration of $250 \mathrm{mg} / \mathrm{kg} \mathrm{5-FU.} P<0.05$ versus WT (ANOVA); ${ }^{*} P<0.05$ versus respective WT $(n=11)$. (H) Survival of Plaur ${ }^{-1-}$ mice after treatment with $250 \mathrm{mg} / \mathrm{kg} \mathrm{5-FU} \mathrm{i.v.} \mathrm{was} \mathrm{reduced} \mathrm{compared} \mathrm{with} \mathrm{WT} \mathrm{mice.} P<0.05$ versus WT, Cox regression analysis $(n=11)$.

teolytically inactivated $(4,27,28)$. We hypothesized that a similar cleavage of ${ }^{\mathrm{M}} \mathrm{uPAR}$ would allow $\mathrm{M}_{\mathrm{uPAR}}{ }^{+}$HSPCs to become mobilized. Of the proteases capable of cleaving recombinant uPAR in vitro (13), we studied the involvement of plasmin in particular, as active plasmin was undetectable in the BM under steady-state conditions but transiently upregulated during HSPC mobilization (Supplemental Figure 3A). Furthermore, plasmin was capable of cleaving ${ }^{\mathrm{M}} \mathrm{uPAR}$ on intact cells in vitro (Supplemental Figure 3B). Moreover, we recently showed that plasmin regulates hematopoietic recovery after cytotoxic myeloablation (29).

\section{Figure 3}

MUPAR regulates HSPC homing, adhesion, and engraftment. (A) Homing of BMCs in lethally irradiated nonsplenectomized recipient mice. Compared with control IgG, pretreatment with $2 \mu \mathrm{g}$ anti-MuPAR per $10^{6}$ cells reduced the number of GFP+ BMCs homing to the BM, but not to the spleen, 5 days after transplantation of $5 \times 10^{6}$ donor cells. ${ }^{*} P<0.05$ versus control IgG $(n=4)$. (B) Homing and early engraftment of Ly5.1+ Lin $^{-} \mathrm{CKit}^{+}$HSPCs to the BM of lethally irradiated splenectomized Ly5.2+ recipient mice. Compared with control IgG, pretreatment with anti-MuPAR inhibited the homing and early engraftment of HSPCs to the BM 5 days after transplantation. ${ }^{\star} P<0.05$ versus control IgG $(n=5-6)$. (C-E) Adhesion of $5 \times 10^{4} \mathrm{WT} \mathrm{Lin}^{-} \mathrm{CKit}+\mathrm{HSPCs}$ to a monolayer of OP9 mouse BM stromal cells (C), sVCAM-1 (D), or fibronectin $(\mathrm{E})$. Compared with control IgG, pretreatment with anti-MuPAR inhibited HSPC adhesion. ${ }^{*} P<0.05$ versus control $\lg G(n=8)$. (F) Compared with control IgG, fewer lethally irradiated splenectomized WT mice survived when transplanted with $1 \times 10^{5}$ WT BMCs pretreated with anti-MuPAR, indicating that the expression of MuPAR on HSPCs promotes engraftment. $P<0.05$ versus control (Cox regression; $n=10$ ).
A
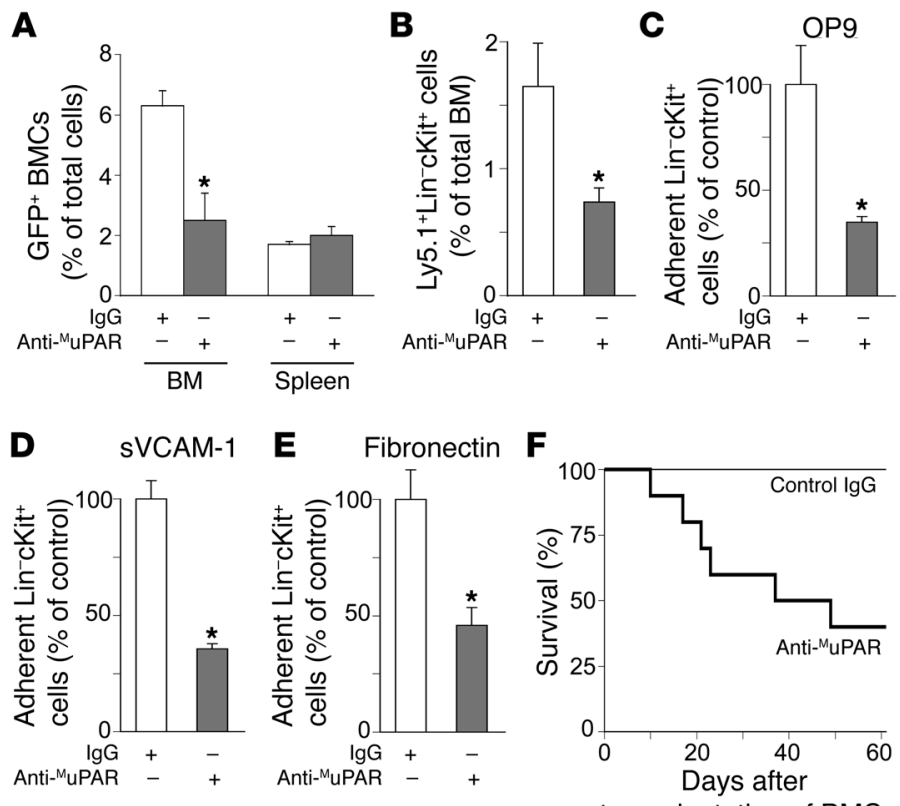


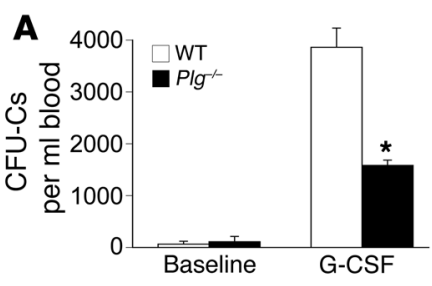

C
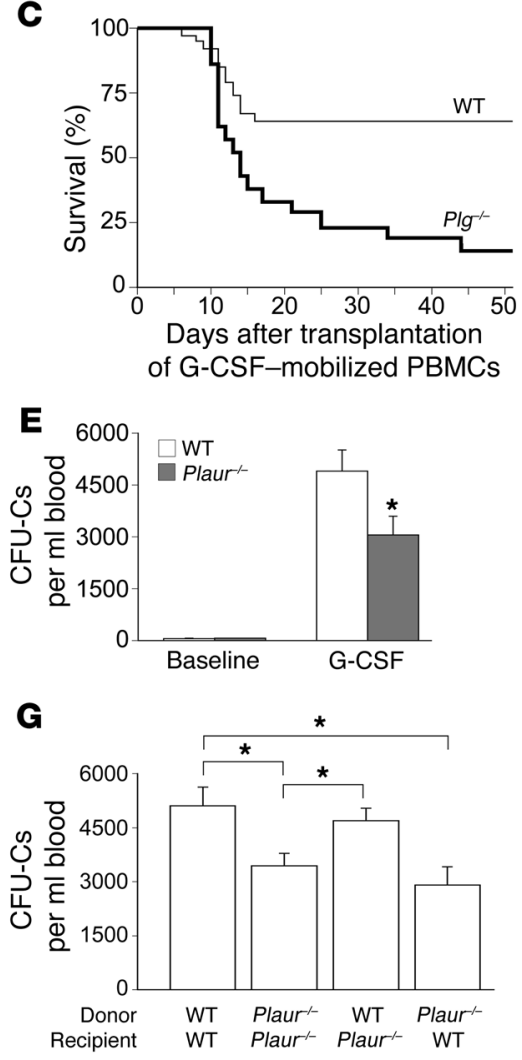
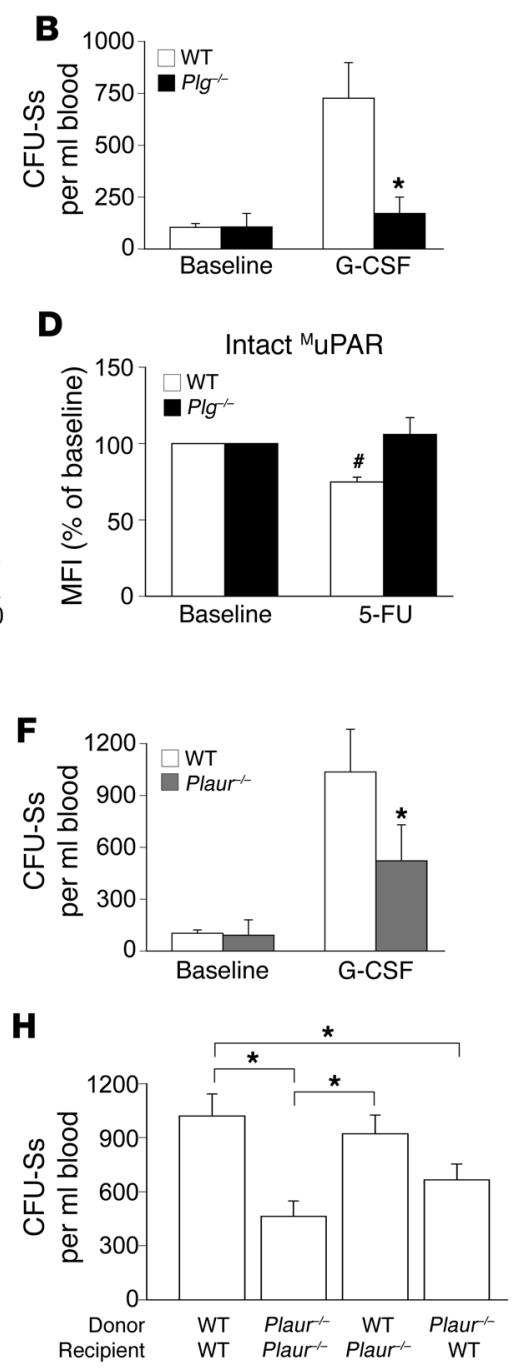

\section{Figure 4}

Impaired HSPC mobilization in $\mathrm{Plg}^{-/-}$mice. (A and $\left.\mathbf{B}\right)$ Fewer circulating CFU-Cs (A) and CFU-Ss (B) were observed in $\mathrm{Plg}^{-/-}$mice 5 days after G-CSF treatment, but not in steady-state conditions. ${ }^{*} P<0.05$ versus WT $(n=8-15)$. (C) Fewer lethally irradiated syngeneic WT recipients survived after transplanting $1 \times 10^{5}$ PBMCs from G-CSF-treated $\mathrm{Plg}^{-1-}$ mice than from WT mice. $P<0.05$, Cox regression analysis $(n=20-39)$. (D) The median fluorescence intensity (MFI) BR4 signal, which specifically recognizes only intact MuPAR (see Methods), on Sca-1+ BMCs was reduced 2 days after 5-FU treatment in WT but not $P l g^{-1-}$ mice. $\# P<0.05$ versus baseline $(n=4)$. ( $(E$ and F) Fewer circulating CFU-Cs $(E)$ and CFU-Ss (F) were observed in Plaur ${ }^{-1}$ mice 5 days after G-CSF treatment, but not in steady-state conditions. ${ }^{*} P<0.05$ versus WT $(n=11-15)$. ( $(\mathbf{G}$ and $\mathbf{H})$ Compared with controls, fewer CFU-Cs (G; $n=12-18$ ) and CFU-Ss $(\mathbf{H} ; n=10)$ were mobilized after G-CSF treatment in Plaur ${ }^{-1}$ or WT recipients of Plaur ${ }^{-1-}$ BM transplant. Transplantation of WT BM into Plaur ${ }^{-1}$ recipients completely restored CFU-C and CFU-S mobilization after G-CSF treatment. ${ }^{*} P<0.05$
To assess whether plasmin regulates the release of $\mathrm{MPAR}^{+} \mathrm{HSPCs}$ from their BM microenvironment in vivo, we tested whether G-CSF, the clinically most common mobilization agent, would mobilize fewer HSPCs in the peripheral blood of $\mathrm{Plg}^{-1-}$ mice, which cannot generate plasmin (30). Fewer CFU-Cs and spleen-derived CFUs (CFU-Ss) were mobilized in $\mathrm{Plg}^{-1-}$ than WT mice (15- versus 63-fold and 1.5-versus 7-fold, respectively, relative to baseline) after administration of $200 \mu \mathrm{g} / \mathrm{kg} / \mathrm{d}$ G-CSF s.c. for 5 days (Figure 4, A and B). Consistent herewith, fewer WT recipients of PBMCs from $\mathrm{G}-\mathrm{CSF}$-treated $\mathrm{Plg}^{-1-}$ mice survived compared with recipients of G-CSF-treated WT PBMCs (Figure 4C). Similar results were obtained in WT mice treated with the plasmin(ogen) inhibitor tranexamic acid (data not shown).

To evaluate whether the HSPC mobilization defect in $\mathrm{Plg}^{-1-}$ mice is caused, at least in part, by impaired cleavage of ${ }^{\mathrm{M}} \mathrm{uPAR}$, we sought more direct evidence for a role of plasmin in the cleavage of $\mathrm{M}_{\mathrm{uPAR}}$. Flow cytometry with an antibody that specifically recognized only the intact form of ${ }^{\mathrm{M}} \mathrm{uPAR}$ revealed that during mobilization, surface levels of intact ${ }^{\mathrm{M}} \mathrm{uPAR}$ on a HSPC-enriched BMC population of $\mathrm{Lin}^{-} \mathrm{Sca}-1^{+}$cells (31) were decreased in WT mice (Figure 4D; see Supplemental Results for rationale of the 5-FU model). As the total level of ${ }^{\mathrm{M}} \mathrm{uPAR}$ did not change (i.e., combined cleaved and intact forms; Supplemental Results), this reduction is likely caused by proteolytic cleavage of ${ }^{\mathrm{M}} \mathrm{UPAR}$. In contrast, such a reduction of intact ${ }^{\mathrm{M}} \mathrm{uPAR}$ was not observed in $\mathrm{Plg}^{-/}$mice (Figure 4D), which suggests that plasmin regulates cleavage of ${ }^{\mathrm{MPAR}}$. Overall, these data are consistent with a model whereby plasmin-mediated cleavage of $\mathrm{M}$ uPAR facilitates HSPC mobilization.

We also studied the mobilization of HSPCs in Plaur ${ }^{-1}$ mice. In steady-state conditions, the number of CFU-Cs and CFU-Ss in the peripheral blood was comparable in WT and Plaur ${ }^{-1}$ mice (Supplemental Results and Figure 4, E and F). Administration of $200 \mu \mathrm{g} / \mathrm{kg} / \mathrm{d}$ G-CSF s.c. for 5 days to WT mice induced a 82-fold increase in CFU-Cs and a 10-fold increase in immature CFU-Ss in the peripheral blood (Figure 4, E and F). In contrast, in Plaur ${ }^{-1}$ mice, significantly fewer CFU-Cs and CFU-Ss (44- and 5.5-fold, respectively, relative to baseline) were mobilized after G-CSF treatment (Figure 4, E and F). Further studies using BM crossover transplantations revealed that transplantation of WT BMCs in Plaur $^{/-}$recipients completely restored the impaired mobilization of CFU-Cs and CFU-Ss after G-CSF treatment, while transplantation of Plaur $^{-1}$ BMCs in WT recipients impaired mobilization (Figure $4, \mathrm{G}$ and $\mathrm{H}$ ). Thus, expression of ${ }^{\mathrm{M}} \mathrm{uPAR}$ on HSPCs is required for HSPC mobilization in response to G-CSF. 

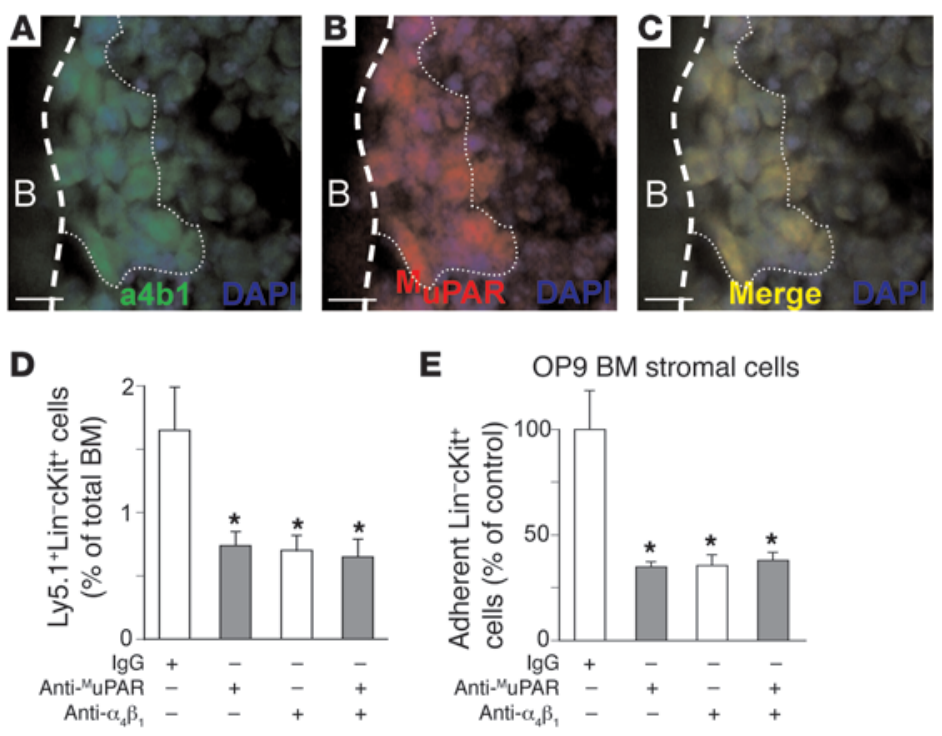

$\mathbf{F}$

SVCAM-1

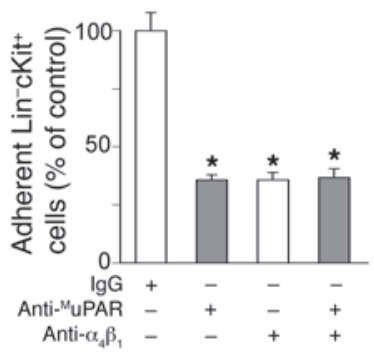

G

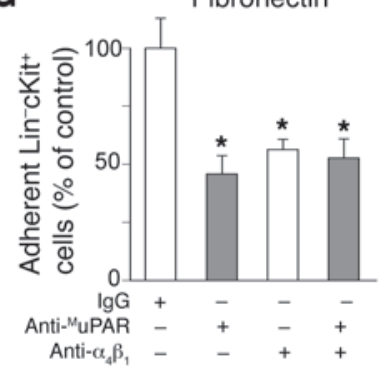

\section{Figure 5}

Molecular mechanisms of MuPAR. (A-C) Double-fluorescent immunostaining of a longitudinal section through the femur, followed by nuclear DAPI staining (blue), revealed the expression of $\alpha_{4} \beta_{1}$ (green; A) and MuPAR (red; B) near the endosteal bone. The merged image (C) shows coexpression of $\alpha_{4} \beta_{1}$ and MuPAR on the same cells near the endosteal bone (yellow). Dashed line demarcates the border between cortical bone (B) and BM; dotted line distinguishes the bone (left) from the bone marrow cavity (right). Scale bars: $10 \mu \mathrm{m}$. (D) Homing and early engraftment of Ly5.1+ Lin-cKit $^{+}$HSPCs to the BM of lethally irradiated splenectomized Ly5.2+ recipient mice. Compared with control IgG, pretreatment with $2 \mu \mathrm{g}$ anti- $\alpha_{4} \beta_{1}$ per $10^{6}$ cells inhibited the homing and early engraftment of HSPCs to the BM 5 days after transplantation. Anti-MuPAR did not further reduce homing and early engraftment when $\alpha_{4} \beta_{1}$ was inhibited, which suggests that MuPAR and $\alpha_{4} \beta_{1}$ act in the same pathway. Data with antiMuPAR from Figure $3 \mathrm{~B}$ are repeated for comparison. ${ }^{*} P<0.05$ versus control IgG $(n=5-6)$. (E-G) Adhesion of $5 \times 10^{4}$ WT $\mathrm{Lin}^{-} \mathrm{CKit}^{+} \mathrm{HSPC}$ to OP9 mouse BM stromal cells (E), sVCAM-1 $(\mathbf{F})$, or fibronectin $(\mathbf{G})$. Compared with control lgG, pretreatment with anti- $\alpha_{4} \beta_{1}$ inhibited HSPC adhesion. Anti-MuPAR did not further reduce adhesion when $\alpha_{4} \beta_{1}$ was inhibited, which suggests that MuPAR and $\alpha_{4} \beta_{1}$ act in the same pathway. Data with anti-MuPAR from Figure 3, C-E, are repeated for comparison. ${ }^{*} P<0.05$ versus control $\lg \mathrm{G}(n=8)$.
Initial insight into the molecular mechanisms of ${ }^{M} u P A R$. We then sought to determine via which molecular mechanisms ${ }^{\mathrm{M}} \mathrm{uPAR}$ acts. $\alpha_{4} \beta_{1}$ Integrin is a critical regulator of adhesion, homing, and engraftment of HSPCs $(26,32,33)$. Previous studies also documented that the function of $\alpha_{4} \beta_{1}$ on cell types other than HSPCs is tightly regulated by an interaction with ${ }^{\mathrm{M}} \mathrm{UPAR}$ in cis, but only when ${ }^{\mathrm{M}} \mathrm{UPAR}$ is intact (i.e., not cleaved; refs. 16, 34), as proteolytic removal of the $D_{\text {I }}$ domain from ${ }^{\mathrm{M}} \mathrm{uPAR}$ (e.g., by plasmin) suffices to abrogate $\beta_{1}$ integrin-dependent cellular adhesion (34). We therefore assessed whether ${ }^{\mathrm{M}} \mathrm{UPAR}$ and $\alpha_{4} \beta_{1}$ cooperatively regulated HSPC adhesion to the BM microenvironment, homing, and engraftment.

We first examined whether ${ }^{\mathrm{M}} \mathrm{UPAR}$ and $\alpha_{4} \beta_{1}$ are coexpressed on HSPCs. Double immunostaining showed that BMCs coexpressing ${ }^{\mathrm{M}} \mathrm{uPAR}$ and $\alpha_{4} \beta_{1}$ resided along the endosteum (Figure 5, A-C). Confocal microscopy further revealed that, upon adhesion of $\mathrm{Lin}^{-} \mathrm{CKit}^{+}$ HSPCs to VCAM-1, ${ }^{\mathrm{u}} \mathrm{uPAR}$ seemed to cluster, at least in part, with $\alpha_{4} \beta_{1}$ on the cell surface (Supplemental Figure 4 , A and B). This effect was specific, as ${ }^{\mathrm{M}} \mathrm{uPAR}$ failed to cluster with $\alpha_{5} \beta_{1}$ (data not shown).

We next tested whether ${ }^{\mathrm{M}}$ uPAR promotes adhesion to the BM microenvironment and homing of HSPCs through cooperation with $\alpha_{4} \beta_{1}$. We first assayed adhesion in vitro, as HSPCs need to adhere to matrix components in the BM microenvironment for homing and engraftment. Incubation of $\mathrm{Lin}^{-} \mathrm{CKit}^{+} \mathrm{HSPCs}$ with blocking anti- $\alpha_{4} \beta_{1}$ antibody inhibited their adhesion to immobilized soluble VCAM-1 (sVCAM-1), fibronectin, or a monolayer of OP9 BM stromal cells (Figure 5, E-G). However, adhesion was not further inhibited when $\mathrm{Lin}^{-} \mathrm{CKit}^{+}$HSPCs were incubated with a combination of anti- $\alpha_{4} \beta_{1}$ and anti-M uPAR (Figure 5, E-G), con- sistent with a model whereby both ${ }^{\mathrm{M}} \mathrm{UPAR}$ and $\alpha_{4} \beta_{1}$ act through similar pathways. Similar results were obtained when analyzing homing and early engraftment of $\mathrm{Lin}^{-} \mathrm{CKit}^{+} \mathrm{HSPC}$ to the BM in vivo (Figure 5D), which indicates that the cooperation between ${ }_{\mathrm{uPAR}}$ and $\alpha_{4} \beta_{1}$ was not restricted to experimental in vitro conditions, but was also operational in vivo. The functional cooperation between ${ }^{\mathrm{M}} \mathrm{uPAR}$ and $\alpha_{4} \beta_{1}$ on HSPCs was specific, as inhibition (or loss) of ${ }^{\mathrm{M}} \mathrm{uPAR}$ did not reduce $\alpha_{4} \beta_{1}$ expression on $\mathrm{Lin}^{-} \mathrm{cKit}^{+}$ HSPCs (data not shown), nor did it reduce the HSPC adhesion, homing, and early engraftment mediated by other signals such as CXCR-4 or cKit (Supplemental Figure 4, C and D). Thus, ${ }^{\mathrm{M}} \mathrm{uPAR}$ regulates adhesion to the $\mathrm{BM}$ microenvironment, homing, and engraftment of HSPCs, at least in part through cooperation with the adhesive signal $\alpha_{4} \beta_{1}$.

Loss of ${ }^{M}$ UAR impairs long-term engraftment and multilineage repopulation. As ${ }^{\mathrm{M}} \mathrm{uPAR}$ on HSPCs is required for marrow pool size preservation, short-term engraftment, homing, adhesion, cell cycle regulation, and mobilization, we next analyzed whether ${ }^{\mathrm{M}} \mathrm{uPAR}$ also plays a role in HSC function. Immunophenotyping revealed that ${ }^{\mathrm{M}} \mathrm{uPAR}$ was also expressed on cells more highly enriched for primitive BM progenitors (i.e., on $36 \% \pm 4 \%$ of $\mathrm{Lin}^{-} \mathrm{Sca}-1^{+} \mathrm{cKit}^{+}$ cells; $n=3$; Supplemental Figure 5). Moreover, compared with WT mice, Plaur ${ }^{--}$mice had $20 \%$ fewer $\mathrm{Lin}^{-} \mathrm{Sca}-1^{+} \mathrm{cKit}^{+}$cells in their BM in steady-state conditions (WT, $26 \pm 1 \times 10^{3}$ cells per 2 femurs; Plaur $^{-1}, 22 \pm 1 \times 10^{3}$ cells per 2 femurs; $\left.n=4 ; P<0.05\right)$. We then analyzed whether loss of $\mathrm{M}_{\mathrm{uPAR}}$ impaired long-term engraftment and multilineage repopulation of the hematopoietic system. Ideally, we would have compared the competitive repopulation abil- 
Table 1
Long-term multilineage competitive repopulation assays with Plaur--_BMMCs

GFP+ WT and Plaur $^{-1}$ donor (test) cells were mixed in a 1:1 or 3:1 ratio with GFP- Plaur ${ }^{-1}$ and WT competitor cells, respectively, and a total of $1 \times 10^{6}$ BMMCs were transplanted into sublethally irradiated GFP-WT recipients. Primary GFP- WT recipient mice were analyzed 24 weeks after transplantation, and the chimerism of GFP+ donor cells in the blood is shown $(n=6-10)$. ANumber per $1 \times 10^{6}$ donor BMMCs. ${ }^{\mathrm{B}} P<0.05$ versus WT/Plaur ${ }^{-1}(1: 1)$. ${ }^{\mathrm{C} P}<0.05$ versus WT/Plaur ${ }^{-1}(3: 1)$.

\begin{tabular}{|c|c|c|c|c|c|c|}
\hline Test/competitor (ratio) & CRUA & PBMCs & Neutrophils & Monocytes & B lymphocytes & T Iymphocytes \\
\hline WT/Plaur ${ }^{-1-}(1: 1)$ & $43 \pm 5$ & $51 \% \pm 3 \%$ & $62 \% \pm 3 \%$ & $38 \% \pm 4 \%$ & $35 \% \pm 4 \%$ & $25 \% \pm 4 \%$ \\
\hline WT/Plaur--- (3:1) & $60 \pm 5^{B}$ & $59 \% \pm 2 \% B$ & $64 \% \pm 3 \%$ & $41 \% \pm 4 \%$ & $36 \% \pm 3 \%$ & $36 \% \pm 6 \%$ \\
\hline Plaur-/-NT (1:1) & $15 \pm 5^{\mathrm{B}}$ & $24 \% \pm 5 \% B$ & $31 \% \pm 9 \% B$ & $21 \% \pm 5 \% \mathrm{~B}$ & $18 \% \pm 5 \% B$ & $11 \% \pm 3 \% B$ \\
\hline Plaur-1-/WT (3:1) & $18 \pm 3^{c}$ & $29 \% \pm 4 \% c$ & $35 \% \pm 4 \% c$ & $25 \% \pm 4 \% c$ & $22 \% \pm 3 \% c$ & $14 \% \pm 3 \% c$ \\
\hline
\end{tabular}

WT recipients. The contribution of donor Plaur ${ }^{--}$Ly5.2 $2^{+}$ cells to the peripheral blood of secondary Ly $5.1^{+}$recipients was significantly lower than that of WT Ly5.2 $2^{+}$cells at both 8 and 24 weeks after transplantation and resulted in fewer CRUs (Figure 6, A-C). Thus, loss of ${ }^{\mathrm{M}} \mathrm{uPAR}$ impaired the ability of BMMCs to engraft and longterm multilineage repopulate primary and secondary recipients, an observation ity of isolated ${ }^{\mathrm{M}} \mathrm{uPAR}^{+}$and ${ }^{\mathrm{M}} \mathrm{UPAR}^{-}$BMCs; however, because the anti- ${ }^{\mathrm{M}} \mathrm{uPAR}$ antibody blocks its function, such studies could not be performed. Similar problems were encountered previously by others when isolating CXCR- $4^{+}$and $\alpha_{4} \beta_{1}{ }^{+}$cells $(35,36)$. We therefore studied the role of ${ }^{\mathrm{M}} \mathrm{uPAR}$ in HSC engraftment by comparing the competitive repopulation ability of BMCs from WT and Plaur $^{-1}$ mice. To identify the transplanted donor cells, cells were harvested from WT and Plaur ${ }^{-1}$ mice that had been intercrossed with Actb:GFP mice. WT and Plaur ${ }^{-}-\mathrm{GFP}^{+}$cells were mixed in a 3:1, 1:1, or 1:3 ratio with Plaur $^{-1}$ and WT GFP- competitor cells, respectively. Compared with $\mathrm{WT} \mathrm{GFP}^{+}$cells, transplantation of Plaur $^{--} \mathrm{GFP}^{+} \mathrm{BM}$ mononuclear cells (BMMCs) in WT recipients resulted in fewer $\mathrm{GFP}^{+}$blood cells and competitive repopulation units (CRUs; calculated as described previously; refs. 37, 38) at 24 weeks after transplantation (Table 1). Even when 3-fold more Plaur $^{-1} \mathrm{GFP}^{+}$BMMCs were cotransplanted with WT GFP- competitor cells, only $30 \%$ of $\mathrm{GFP}^{+}$cells were detected in the blood of recipient mice after 24 weeks (Table 1). Multilineage analysis of the peripheral blood 24 weeks after transplantation confirmed the competitive disadvantage of $\mathrm{Plaur}^{--} \mathrm{GFP}^{+}$BMMCs: fewer $\mathrm{GFP}^{+} \mathrm{Gr} 1 \mathrm{CD} 11 \mathrm{~b}^{\text {hi }}$ granulocytes, $\mathrm{GFP}^{+} \mathrm{Gr} 1 \mathrm{CD} 11 \mathrm{~b}^{\text {lo }}$ monocytes, $\mathrm{GFP}^{+} \mathrm{B} 220^{+} \mathrm{B}$ lymphocytes, and $\mathrm{GFP}^{+} \mathrm{CD} 3 \mathrm{e}^{+} \mathrm{T}$ lymphocytes were detected (Table 1). This defect was specific, as the total blood counts between the experimental groups were comparable (data not shown).

We also performed serial transplantations. Donor WT or Plaur ${ }^{-/}$BMMCs were transplanted in primary recipients subjected to sublethal irradiation (8 Gy). BM from these animals was then transplanted in secondary animals, and the contribution of the donor cells to the hematopoietic system was analyzed (39). To distinguish donor from host cells, we used donor and recipient mice expressing the leukocyte markers Ly5.2 and Ly5.1, respectively. Compared with WT Ly5.2+ donor BMMCs, noncompetitive transplantation of $5 \times 10^{5} \mathrm{Plaur}^{--}$Ly5.2 $2^{+}$ donor cells resulted in equal donor contribution to blood cells in primary WT recipient mice (data not shown). At 10 weeks after transplantation, $5 \times 10^{5}$ BMMCs from primary recipient mice were transplanted into secondary Ly5.1 $1^{+}$ compatible with the finding that Plaur $^{-/}$mice had fewer HSCs in the BM in steady-state conditions.

\section{Discussion}

The present findings indicate that ${ }^{\mathrm{M}} \mathrm{uPAR}$ is present on a subpopulation of HSPCs and, similar to $\alpha_{4} \beta_{1}$ and Tie-2 $(22,32)$, regulates their cell-cycle status, thereby preventing abnormal HSPC proliferation and apoptosis while ensuring chemoprotection. ${ }^{\mathrm{M}} \mathrm{UPAR}$ also promotes adhesion of HSPCs to the BM microenvironment, as well as homing and engraftment of HSPCs, similar to $\alpha_{4} \beta_{1}$ and CXCR-4 (26, 33, 40, 41). Our data also show that ${ }^{\mathrm{M}} \mathrm{uPAR}$ is cleaved during mobilization of HSPCs, similar to cKit $(42,43)$. We thus conclude that ${ }^{\mathrm{M}} \mathrm{UPAR}$ is a receptor on HSPCs that regulates various processes of HSPCs in the BM.

For HSPCs to become mobilized from their BM microenvironment, adhesive signals must become inactivated $(4,28)$. Our findings using antibodies specifically recognizing intact ${ }^{\mathrm{M}} \mathrm{uPAR}$ versus all forms of ${ }^{\mathrm{M}} \mathrm{uPAR}$ (i.e., including $\mathrm{D}_{\mathrm{II}} \mathrm{D}_{\mathrm{III}}$ ) indicate that the intact ${ }_{\mathrm{U}}^{\mathrm{uPAR}}$ signal on a HSPC-enriched BMC population was reduced during mobilization in WT mice. As the signal of total ${ }^{\mathrm{M}} \mathrm{uPAR}$ was not changed, the reduction of the intact ${ }^{\mathrm{M}} \mathrm{uPAR}$ signal is likely caused by proteolytic cleavage. Such a decrease did not occur in $\mathrm{Plg}^{-/-}$mice, which suggests that plasmin regulates cleavage of ${ }_{\mathrm{M}}^{\mathrm{uPAR}}$. Moreover, this proteinase is transiently upregulated in the
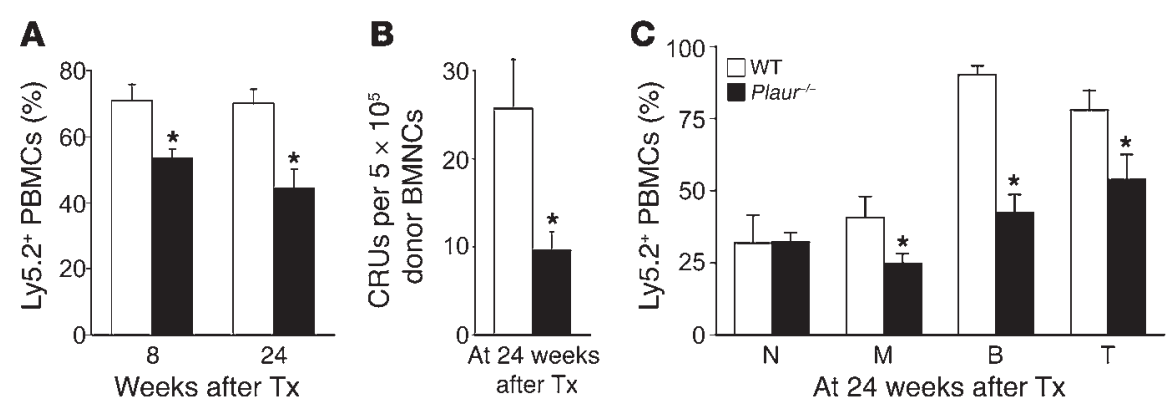

\section{Figure 6}

Loss of uPAR impairs long-term engraftment and multilineage repopulation. (A-C) Serial transplantation assay showed a significantly reduced contribution of Plaur ${ }^{-1-}$ Ly5.2 $2^{+}$donor cells to the hematopoietic system in secondary Ly5.1+ recipients. (A) Percentage of Ly5.2+ PBMCs in secondary Ly5.1+ recipient mice at 8 and 24 weeks after transplantation (Tx). (B) Number of CRUs per $5 \times 10^{5}$ BMMCs in secondary Ly5.1+ recipient mice at 24 weeks after transplantation. (C) Multilineage repopulation in secondary Ly5.1+ recipient mice at 24 weeks after transplantation, revealing the percentage of GFP+ neutrophils (Gr1CD11 b $\left.\mathrm{b}^{\text {i }} \mathrm{N}\right)$, monocytes (Gr1CD11blo; M), B lymphocytes (B220+; B) and T lymphocytes (CD3e+; T). ${ }^{*} P<0.05$ versus WT donor cells $(n=6-9)$. 
BM during mobilization, and HSPC mobilization was impaired in $\mathrm{Plg}^{-1-}$ mice. In addition, we showed that plasmin cleaved ${ }^{\mathrm{M}} \mathrm{uPAR}$ on intact cells in vitro, confirming previous findings that it cleaves recombinant ${ }^{\mathrm{s}} \mathrm{uPAR}$ in vitro (13). Furthermore, ${ }^{\mathrm{s}} \mathrm{uPAR}$ levels increased during mobilization in WT but not $\mathrm{Plg}^{-1-}$ mice (data not shown), and the number of ${ }^{\mathrm{M}} \mathrm{UPAR}{ }^{+} \mathrm{Sca}-1^{+}$cells retained in the BM after 5-FU mobilization was higher in $\mathrm{Plg}^{-1-}$ than in WT mice. Therefore, plasmin is a likely candidate proteinase to inactivate ${ }^{\mathrm{M}} \mathrm{uPAR}$ on HSPCs during mobilization. Our findings do not exclude the possibility that plasmin may also regulate HSPC mobilization via additional mechanisms, such as via cleavage of $\mathrm{mKitL}$ - as suggested by the reduced cleavage of mKitL in $\mathrm{Plg}^{-1-}$ mice (our unpublished observations and refs. 29, 44).

Loss of ${ }^{\mathrm{u}} \mathrm{uAR}$ caused a partial depletion of HSPCs in the BM; however, this was not accompanied by elevated HSPC counts in the peripheral blood or spleen. These data suggest that ${ }^{\mathrm{M}} \mathrm{uPAR}$, besides functioning as an adhesive signal as described above, also regulates the marrow pool size of a subpopulation of $\mathrm{MPAR}^{+}$ HSPCs that is dispensable for baseline hematopoiesis, but responsive to mobilization signals. Indeed, if ${ }^{\mathrm{M}} \mathrm{uAR}$ functioned solely as an adhesive signal, then HSPC counts in the peripheral blood would be elevated in Plaur ${ }^{/-}$mice, similar to when the adhesive signals CXCR- 4 or $\alpha_{4}$ integrin are inactivated in BMCs $(26,41)$. How ${ }^{\mathrm{M}} \mathrm{UPAR}$ regulates the marrow pool size of HSPCs remains to be determined, but this receptor has been previously documented to regulate the maintenance of neurons as well (45). Regardless of the mechanisms, ${ }^{\mathrm{M}} \mathrm{uPAR}$ thus resembles other HSPC receptors, such as Tie- 2 and cKit, that are also essential for HSPC marrow pool size and adhesion to the BM microenvironment $(1,3,22)$.

Previous reports show that ${ }^{\mathrm{M}} \mathrm{uPAR}$ regulates endothelial adhesion and transmigration of various leukocyte subtypes through integrin-dependent and -independent mechanisms (reviewed in ref. 12). As HSPCs use similar adhesion receptors to interact with the endothelium and extravasate during homing (46), it is conceivable that ${ }^{\mathrm{M}} \mathrm{uPAR}$ may also regulate endothelial adhesion and transmigration of HSPCs via similar mechanisms.

Our findings do not allow us to conclude that expression of ${ }^{\mathrm{M}} \mathrm{uPAR}$ on HSPCs per se regulates the anchorage-dependent cell cycle, even though ${ }^{\mathrm{M}} \mathrm{uPAR}$ can regulate the cell cycle (47). Rather, we favor the interpretation that the observed differences in the proliferation status between ${ }^{\mathrm{M}} \mathrm{uPAR}^{+}$and ${ }^{\mathrm{M}} \mathrm{UPAR}^{-}$HSPCs might be explained, at least in part, by assuming that the ${ }^{\mathrm{M}} \mathrm{uPAR}^{+}$ HSPC is a different type of progenitor. ${ }^{\mathrm{M}} \mathrm{uPAR}$ may well identify a specific HSPC population that is critically involved in homing, engraftment, and mobilization. Consistent herewith, ${ }^{\mathrm{uPAR}}{ }^{+}$ HSPCs proliferated less, a finding compatible with prior observations that HSPCs that proliferate less also home and engraft better to the BM (48).

The present study was not designed to unravel the nature of the molecular interactions between ${ }_{\mathrm{M}}^{\mathrm{uPAR}}$ and $\alpha_{4} \beta_{1}$, but to characterize the role of ${ }^{\mathrm{M}} \mathrm{uPAR}$ in HSPC biology and, in a second stage, explore how ${ }^{\mathrm{M}} \mathrm{uPAR}$ might exert this biological activity. Initial analysis suggests that cooperation of ${ }^{\mathrm{M}} \mathrm{UPAR}$ with $\alpha_{4} \beta_{1}$ may explain some of the effects of ${ }^{\mathrm{M}} \mathrm{UPAR}$ on HSPCs. It is known that $\alpha_{4} \beta_{1}$ regulates the migration and adhesion of HSPCs to fibronectin and VCAM-1 during their homing and engraftment in the BM $(26,32,33,40)$. The function of $\alpha_{4} \beta_{1}$ is also known to depend on the presence of intact ${ }^{\mathrm{M}} \mathrm{uPAR}$, as only intact ${ }^{\mathrm{M}} \mathrm{uPAR}$ interacts with the integrin in cis $(16,34)$. In fact, removal of $D_{I}$ from ${ }^{M}$ UPAR is known to reduce $\alpha_{4} \beta_{1}$-mediated cellular adhesion in vitro (34).
Thus, when ${ }^{\mathrm{M}} \mathrm{uPAR}$ was entirely absent, such as in Plaur $^{-1-}$ mice, or inactive, such as after preincubation of WT HSPCs with anti${ }_{\mathrm{uPAR}}$, adhesion of $\alpha_{4} \beta_{1}{ }^{+}$HSPCs to the BM matrix was reduced, likely explaining why homing and engraftment of HSPCs were impaired. Likewise, in WT mice, when $\mathrm{D}_{\mathrm{I}}, \mathrm{D}_{\mathrm{II}} \mathrm{D}_{\text {III }}$, or $\mathrm{D}_{\mathrm{I}} \mathrm{D}_{\mathrm{II}} \mathrm{D}_{\text {III }}$ was proteolytically cleaved from ${ }^{\mathrm{M}} \mathrm{uPAR}$ by plasmin, as occurs during HSPC mobilization, adhesion of $\alpha_{4} \beta_{1}{ }^{+}$HSPCs to the BM matrix was reduced and mobilization favored. Further evidence for this model is deduced from our findings that anti- $\alpha_{4} \beta_{1}$ antibodies could not further aggravate the adhesion defects of HSPCs when ${ }^{\mathrm{M}} \mathrm{uPAR}$ was absent or blocked, and by the observation that homing and engraftment defects were similar in mice lacking functional ${ }_{\mathrm{u}} \mathrm{uAR}$ or $\alpha_{4} \beta_{1}(25,26,49)$. Whether $\mathrm{M}_{\mathrm{UPAR}}$ cooperates with $\alpha_{4} \beta_{1}$ on HSPCs directly via formation of a complex, or instead indirectly through association with intermediate binding partners, remains to be investigated. Our data do not exclude the possibility that ${ }^{\mathrm{M}} \mathrm{uPAR}$, alone or together with $\alpha_{4} \beta_{1}$, might act via additional pathways. This is suggested by the finding that depletion of a fraction of HSPCs is observed in mice lacking ${ }^{\mathrm{M}} \mathrm{uPAR}$, but not in mice lacking $\alpha_{4} \beta_{1}$ (26). It also remains outstanding whether ${ }^{\mathrm{M}} \mathrm{uPAR}$, via generation of ${ }^{\mathrm{S}} \mathrm{uPAR}$, may desensitize CXCR-4 and/or induce signaling through fMLP receptors and thereby contribute to HSPC mobilization, a mechanism that has been previously proposed by others $(19,20)$.

Loss of ${ }^{\mathrm{M}} \mathrm{uPAR}$ also impaired the long-term engraftment and multilineage repopulation of primary and secondary myeloablated recipient mice. It is therefore tempting to conclude that ${ }^{\mathrm{M}} \mathrm{uPAR}$ might also regulate the engraftment and mobilization of HSCs, as it does for HSPCs. Consistent herewith, ${ }^{\mathrm{M}} \mathrm{uPAR}$ was expressed on some of the most primitive $\mathrm{Lin}^{-} \mathrm{Sca}-1^{+} \mathrm{CKit}^{+} \mathrm{BM}$ progenitors, and Plaur $^{-1}$ mice exhibited 20\% depletion of the HSC pool in steadystate BM. However, the present findings do not allow us to draw such firm conclusions. The reduced multilineage repopulation of Plaur/- BMMCs we observed in competitive repopulation experiments argues in favor of a model whereby ${ }^{\mathrm{M}} \mathrm{uPAR}$ is required for the engraftment of HSCs. However, we cannot rule out the possibility that our results were affected by altered numbers of engrafting HSCs in the BM of Plaur ${ }^{--}$mice. One method to more definitively prove that ${ }^{\mathrm{M}} \mathrm{UPAR}$ plays a role in HSC function would be

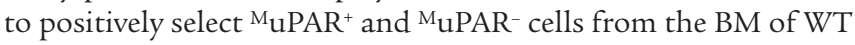
animals and compare their long-term multilineage repopulation ability. Unfortunately, as anti- ${ }^{\mathrm{M}} \mathrm{uPAR}$ antibodies that do not neutralize its function are not available, such studies cannot be performed at present. Hence, it remains to be investigated whether $\mathrm{M}_{\mathrm{UPAR}}$ is present on repopulating HSCs and is responsible, at least in part, for their homing and engraftment. Another question is where in the $\mathrm{BM}^{\mathrm{M}} \mathrm{uPAR}^{+}$HSPCs and HSCs reside.

Our findings might have medical implications. The finding that ${ }_{\mathrm{UPAR}}$ is a functional marker of HSPCs might provide further insights in genetic HSPC disorders such as paroxysmal nocturnal hemoglobinuria, in which ${ }^{\mathrm{M}} \mathrm{uPAR}$ expression on hematopoietic cells, including HSPCs, is absent (12). It will also be of interest to evaluate whether ${ }^{\mathrm{M}} \mathrm{uPAR}$ and plasmin play a role in the dissemination of leukemic cells (50) and in the proliferation and mobilization of leukemic progenitor cells, which share common pathways with HSPCs and contribute to hematopoietic malignancies (51). Finally, thrombolytic agents enhance the mobilization of HSPCs in mice and humans (52), warranting further efforts to analyze the mobilization potential of plasmin therapy in clinical medicine. 


\section{Methods}

Animal studies. WT mice and mice with inactivation of the genes encoding plasminogen (Plg) or uPAR (Plaur) $(30,53)$ - bred in our animal facility or kindly provided by E. Plow (Cleveland Clinic, Cleveland, Ohio, USA), O. Matsuo (Kinki University School of Medicine, Osaka, Japan), T. Ny (Umea University, Umea, Sweden), and V. Ploplis (University of Notre Dame, Notre Dame, Indiana, USA) - were used at 8-12 and 8-16 weeks of age, respectively. For all experiments, age-, gender-, and strain-matched mice were used. In addition, we used Actb:GFP mice - syngeneic mice ubiquitously expressing GFP - obtained from A. Nagy (Samuel Lunenfeld Research Institute, Toronto, Ontario, Canada). Mice were maintained in high-efficiency particulate-filtered IVC units. All experiments were performed according to the guidelines for care and use of laboratory animals approved by the institutional ethical animal care committee of Katholieke Universiteit Leuven. Mice were injected with a bolus of 5-FU i.v. (200 or $250 \mathrm{mg} / \mathrm{kg}$, Fluroblastin; Pharmacia) or with G-CSF s.c. (200 $\mu \mathrm{g} / \mathrm{kg} / \mathrm{d}$, Filgrastrim; Amgen) for 5 consecutive days. Peripheral blood was repetitively sampled by retro-orbital puncture under light anesthesia, and full blood counts (EDTA buffered) were determined on a hemocytometer (Cell-Dyn 1300; Abbott). Peripheral blood smears were stained using Giemsa-May-Grunwald, and at least 200 cells were counted. Tranexamic acid (Exacyl; Bournonville) was administered via osmotic minipumps (1.8 mg/d, Alzet 2001; Charles River) and via the drinking water $(20 \mathrm{mg} / \mathrm{ml})$ as described previously (54).

HSPC assays and transplantation experiments. PBMCs, spleen mononuclear cells, and BMMCs were prepared via Lympholiter-M (Cedarlane; Sanbio) and density centrifugation. For CFU-C assays, $1 \times 10^{4}$ BMCs or $1 \times 10^{5}$ PBMCs or splenic mononuclear cells were plated in $35-\mathrm{mm}$ dishes (Stem Cell Technologies) using methylcellulose supplemented with growth factors (MethoCult; Stem Cell Technologies), and colonies were blindly scored after 7,13, and 13 days, respectively, using an inverted microscope. For CFU-S assays, lethal total-body irradiation $(9.5 \mathrm{~Gy})$ and transplantation of $1-1.5 \times 10^{5}$ mobilized PBMCs were performed in syngeneic WT recipients, and survival was monitored or splenic colonies were blindly scored after 12 days using a dissection microscope. For total BM transplantation, lethal total-body irradiation and transplantation of $5 \times 10^{6}$ unfractionated BMCs were performed in syngeneic recipients, and mice were allowed to recover for at least 6 weeks. Alternatively, $5 \times 10^{5}$ BMMCs of WT and Plaur ${ }^{-1}$ mice were transplanted into primary sublethally irradiated (8 Gy) Ly5.1+ C57BL/6.SJL mice. Flow cytometry revealed that the leukocytes in WT and Plaur/- mice only expressed Ly5.2 (data not shown). At 20 weeks after transplantation, the primary recipients were challenged with $200 \mathrm{mg} / \mathrm{kg} 5$-FU i.v. Hematopoietic reconstitution was determined by flow cytometry using antibodies against Ly5.1, Ly5.2, and lineage markers. For short-term competitive reconstitution assays, BMMCs of WT and Plaur $^{/-} \mathrm{GFP}^{+}$donor mice with equal GFP expression were prepared by density centrifugation and mixed in 1:1 and 3:1 ratios with Plaur $^{-}$and WT GFP- donor BMMCs, respectively. A total of $1 \times 10^{6}$ mixed $\mathrm{GFP}^{+}$and GFP- BMMCs was transplanted into sublethally irradiated WT recipient mice. At 4, 8, and 24 weeks after transplantation, the number of $\mathrm{GFP}^{+}$ cells in the peripheral blood was quantified by flow cytometry. At 24 weeks after transplantation, we also analyzed multilineage reconstitution in the peripheral blood by flow cytometry. As a measure of repopulating capacity, the number of CRUs was calculated as $\left(10 \times\right.$ percent $\mathrm{GFP}^{+}$ repopulation $) /\left(100\right.$ - percent $\mathrm{GFP}^{+}$repopulation), as described previously $(37,38)$. For serial transplantation, $5 \times 10^{5}$ donor BMMCs of WT and Plaur $^{-1}$ mice without competitor cells were transplanted into primary sublethally irradiated C57BL/6.SJL mice. Flow cytometry revealed that the leukocytes in WT and Plaur/- mice only expressed Ly5.2 (CD45.2; data not shown). Flow cytometric analysis of the peripheral blood at 4, 8 and 20 weeks after transplantation revealed no difference in Ly5.2+ blood cells,
Ly5.2+ multilineage reconstitution, or full blood counts between recipient groups (data not shown). BMMCs of primary recipient mice with equal Ly5.2 expression (10 weeks after transplantation; ref. 39) were prepared by density centrifugation, and $5 \times 10^{5}$ donor cells were transplanted without competitor cells into secondary sublethally irradiated C57BL/6.SJL mice. Hematopoietic reconstitution was determined by flow cytometry using antibodies against Ly5.1, Ly5.2, and lineage markers.

Homing and engraftment experiments. For short-term homing, lethal totalbody irradiation and transplantation of $5 \times 10^{6}$ unfractionated BMCs from Actb:GFP mice were performed in syngeneic WT recipients, and $\mathrm{GFP}^{+}$cells in BM and spleen were determined by fluorescence-activated cell sorting (FACS) analysis after 5 days. For long-term engraftment, lethal total-body irradiation and transplantation of $1 \times 10^{5}$ unfractionated BMCs were performed in splenectomized syngeneic WT recipients, and survival was monitored (55). Some cells were preincubated at $37^{\circ} \mathrm{C}$ for $30 \mathrm{~min}$ with rabbit IgG or rabbit anti-mouse ${ }^{\mathrm{M}} \mathrm{uPAR}$ antibodies $\left(2 \mu \mathrm{g}\right.$ per $1 \times 10^{6}$ cells). For shortterm homing of HSPCs, Lin $^{-} \mathrm{CKit}^{+} \mathrm{HSPC}$ harvested from sublethally irradiated Ly5.1+ C57BL/6.SJL mice were isolated via magnetic bead separation (EasySep; Stem Cell Technologies), and transplantation of approximately $1 \times 10^{6}$ HSPCs was performed in lethally irradiated splenectomized Ly5.2 ${ }^{+}$ C57BL $/ 6$ recipient mice. For magnetic bead isolation, the protocol consisted of 1 round of lineage depletion followed by 2 rounds of positive selection for cKit, which resulted in greater than $90 \%$ purity of $\mathrm{Lin}^{-} \mathrm{CKit}^{+} \mathrm{HSPCs}$ (data not shown). For inhibition studies, cells were preincubated at $37^{\circ} \mathrm{C}$ for 30 min with anti- $\alpha_{4} \beta_{1}\left(2 \mu \mathrm{g}\right.$ per $1 \times 10^{6}$ cells, clone PS/2; ATCC; ref. 46), anti$\mathrm{M}_{\mathrm{uPAR}}\left(2 \mu \mathrm{g}\right.$ per $1 \times 10^{6}$ cells) or appropriate controls. Anti- $\alpha_{4} \beta_{1}$ antibodies were purified from hybridoma supernatant. Homing was analyzed by flow cytometry or CFU-C assays. For adhesion assays, 48 -well plates were coated with $5 \times 10^{5}$ cells $/ \mathrm{ml} \mathrm{OP} 9$ mouse stromal cells (ATCC), $5 \times 10^{5}$ cells $/ \mathrm{ml} \mathrm{KitL-}$ deficient mouse stromal cells (SI/SI) transfected with human KitL (SI/SI4 hSCF248, catalog no. CRL-2454; ATCC), $10 \mu \mathrm{g} / \mathrm{ml}$ murine fibronectin in PBS (Invitrogen), or $5 \mu \mathrm{g} / \mathrm{ml}$ murine sVCAM- 1 in PBS (R\&D Systems) and overlaid with $5 \times 10^{4}$ freshly prepared Lin $^{-} \mathrm{CKit}^{+} \mathrm{HSPCs}$, which were labeled with Vybrant CFDA SE Cell Tracer Kit (CFSE; Invitrogen). Labeling efficiency and viability of cells were greater than $95 \%$, as analyzed by FACS. Kinetic experiments revealed that 4 hours of adhesion resulted in optimal evaluation of adhesion properties (data not shown). Inhibition studies were performed as described above. Assays were terminated by gently washing with PBS, and adhered cells were fixed with $2 \%$ phosphate-buffered paraformaldehyde. Analysis was performed on 9 random fields per well at $\times 20$ magnification (LSM 510; Zeiss) and quantified using KS300 software (Zeiss).

FACS analysis. Murine BMCs were filtered through a 40- or 70- $\mu$ m nylon mesh (BD Falcon, BD Biosciences), and peripheral blood cells were treated with rbc lysis buffer. For lineage depletion, we performed magnetic bead isolation (EasySep; Stem Cell Technologies) before flow cytometry. Staining was performed with biotinylated or PE-, FITC- or allophycocyanin-labeled anti-mouse antibodies against the following antigens: Sca-1, CXCR-4, Ly5.1, Ly5.2, Gr-1, CD11b, B220, CD3e, and BrdU (all from BD Biosciences); mouse lineage panel (Miltenyi); and cKit and $\alpha_{4} \beta_{1}$ (eBioscience). Biotinylated antibodies were detected via streptavidin-Alexa Fluor 488 (Invitrogen) or FITC (BD). Control stainings included appropriate isotype control antibodies. Nonspecific binding was prevented by addition of mouse serum (DakoCytomation) as an alternative for Fc receptor block. Flow cytometric analysis was performed on a FACSCalibur flow cytometer equipped with CellQuest software (version 3.3; BD Biosciences) or on a FACSCanto flow cytometer equipped with FACS Diva software (version 5.0.2; BD Biosciences). Expression of mouse ${ }^{\mathrm{M}} \mathrm{uPAR}$ was detected using monoclonal antibodies recognizing either full-length ${ }^{\mathrm{M}} \mathrm{uPAR}$ only $\left(\mathrm{D}_{\mathrm{I}} \mathrm{D}_{\text {III }} \mathrm{D}_{\text {III }}\right.$; clone BR4), or both full-length $\left(\mathrm{D}_{\mathrm{I}} \mathrm{D}_{\mathrm{II}} \mathrm{D}_{\text {III }}\right)$ and cleaved $\left(\mathrm{D}_{\text {III }} \mathrm{D}_{\text {III }}\right)$ forms of ${ }^{\mathrm{M}} \mathrm{UPAR}$ (clone AK17; generated in our laboratory). Expression levels were confirmed with an affin- 
ity-purified rabbit anti-mouse ${ }^{\mathrm{M}} \mathrm{uPAR}$ antibody and with negative staining of $u P A R^{-/-}$BMCs (data not shown). Expression analysis of ${ }^{\mathrm{M}} \mathrm{uPAR}$ on HSPC subpopulations was performed with clone AK17. For analysis of cleavage of ${ }^{\mathrm{M}} \mathrm{uPAR}$, BMCs were double-stained with a FITC-labeled anti-Sca-1 antibody in combination with PE-labeled antibody, clone BR4 or AK17. After gating Sca- $1^{+\mathrm{M}} \mathrm{uPAR}^{\text {hi }}$ cells, median fluorescence intensities of BR 4 or AK17 were measured via histogram plots, and values in 5-FU-treated mice were compared with steady-state conditions. Data were expressed as percent of steady-state condition. For cell-cycle analysis, Lin- BMCs were stained with primary antibodies, fixed in $70 \%$ ethanol, and treated with propidium iodide (PI/RNAse; BD Biosciences), as previously described (4). HSPC low cell-cycle status was evaluated using Pyronin Y (Sigma-Aldrich), as previously described (56). HSPC apoptosis was analyzed using TUNEL staining (fluorescein in situ cell death detection kit; Roche), as described previously (57). To determine HSPC proliferation, mice were injected i.p. with BrdU (1 mg; Sigma-Aldrich) every 8 hours for 2 days, and the fractions of $\mathrm{BrdU}^{+}$ HSPCs were quantified by flow cytometry, as described previously (56).

Anti- ${ }^{M}$ uPAR antibody generation. Recombinant murine ${ }^{\mathrm{S}} \mathrm{uPAR}$ was expressed in Schneider S2 cells using the Drosophila Expression System Kit (Invitrogen). Briefly, the murine uPAR1 cDNA (58) was amplified using primers smuPAR and smuPARr (5'-GATGATATCGATCTCAATATGGGACTCCCAAGGCGG-3' and 5'-ATCGGGCCCGGGGCTGTTACAGCCGCT-3', respectively) and cloned EcoRV/Apa1 in pAc5.1/V5-HisA. Recombinant murine ${ }^{\mathrm{S}} \mathrm{uPAR}$ was purified from the conditioned medium of stably transfected S2 cells using Ni-NTA beads (Qiagen) followed by gel filtration. Rabbits were immunized with recombinant murine ${ }^{\mathrm{s}} \mathrm{uPAR}$, and the IgG fraction of the serum was affinity purified on a column containing immobilized recombinant murine ${ }^{\mathrm{S}} \mathrm{uPAR}$. Monoclonal antibodies against mouse ${ }^{\mathrm{M}} \mathrm{UPAR}$ were raised in Plaur $/-$ mice immunized with recombinant murine ${ }^{\mathrm{S}} \mathrm{uPAR}$. The domain specificity of the antibodies was determined by FACS analysis on HEK293 cells transfected with intact mouse ${ }^{\mathrm{M}}$ uPAR or a mouse ${ }^{\mathrm{M}} \mathrm{uPAR}$ variant lacking $\mathrm{D}_{\mathrm{I}}$. Antibodies were PE-labeled (PhycoLink R-Phycoerythrin conjugation kit; Prozyme) according to the manufacturer's instructions. Antibodies ( $2 \mathrm{mg} / \mathrm{ml}$ in PBS) were biotinylated for $30 \mathrm{~min}$ at room temperature using a 25 -fold molar excess of Sulfo-LC-Biotin (Perbio) followed by extensive dialysis.

Immunohistochemistry. Mice were killed via cervical dislocation, and the femurs were removed, fixed in 2\% paraformaldehyde in PBS for 24 hours, and decalcified in $0.5 \mathrm{M}$ EDTA solution for 8 days. After dehydration and paraffin embedding, $10-\mu \mathrm{m}$ longitudinal sections were prepared on Superfrost Plus slides (Thermo Scientific). Immunohistochemistry was performed using antibodies against $\alpha_{4} \beta_{1}$ (eBioscience), Sca-1, or cKit (BD Biosciences). Mouse ${ }^{\mathrm{M}} \mathrm{uPAR}$ expression was detected using an affinity-purified rabbit anti-mouse ${ }^{\mathrm{M}} \mathrm{uPAR}$ antibody, and specificity of immunostaining was confirmed on WT mouse kidney sections and on BM sections of Plaur/mice (data not shown). For fluorescence imaging, sections were counterstained with DAPI and mounted with Vectashield (Vector Laboratories). Analysis was performed on a Zeiss Axioplan2 connected to a 3-chargedcoupled device video camera (DXC-93OP; Sony) using KS300 software (Zeiss). Clustering of ${ }^{\mathrm{uPAR}}$ was analyzed on freshly isolated $\mathrm{Lin}^{-} \mathrm{CKit}^{+}$ HSPCs, which had been added 4 hours prior to chamber slides (NUNC) coated with sVCAM-1 and stained with antibodies against ${ }^{\mathrm{M}} \mathrm{uPAR}$ (rabbit polyclonal), $\alpha_{4} \beta_{1}$ (eBioscience), or $\alpha_{5} \beta_{1}$ (BD Biosciences). Z-stacks of the cells were obtained and visualized in shadow mode with ZEN 2007 software (Zeiss) and the Zeiss LSM510 META NLO confocal laser scanning module installed on an Axiovert 200M microscope (Zeiss) and equipped with an argon- (488 nm), DPSS- $(561 \mathrm{~nm})$, and femto-second pulsed tunable 2-photon Chameleon laser (720 nm; Coherent).

ELISAs. Murine ${ }^{\mathrm{S}} \mathrm{uPAR}$ was measured by a homemade ELISA using polyclonal antibodies, which were raised against murine ${ }^{S}$ UPAR purified from the conditioned medium of transfected Drosophila S2 cells. These antibodies recognized both $\mathrm{D}_{\mathrm{I}} \mathrm{D}_{\mathrm{II}} \mathrm{D}_{\mathrm{III}}$ and $\mathrm{D}_{\text {III }} \mathrm{D}_{\text {III }}$ of murine ${ }^{\mathrm{s}} \mathrm{UPAR}$. The ELISA was extensively tested for specificity and recovery using plasma of Plaur $/-^{-}$mice spiked with recombinant murine ${ }^{\mathrm{S}} \mathrm{uPAR}$. We coated 96-well ELISA plates (NUNC) with $0.3 \mu \mathrm{g} / \mathrm{ml}$ affinity-purified anti-uPAR antibody in $0.1 \mathrm{M}$ sodium carbonate buffer ( $\mathrm{pH}$ 9.6) overnight at $4{ }^{\circ} \mathrm{C}$ and blocked the remaining binding sites with PBS containing 2\% BSA for 1 hour at room temperature. All subsequent incubations were performed in PBS containing $1 \%$ BSA for 1 hour at room temperature on an orbital shaker set to $100 \mathrm{~g}$ and were spaced by extensive washings using PBS containing $0.01 \%$ Tween-20. Bound mouse ${ }^{\mathrm{S}} \mathrm{uPAR}$ was detected using a biotinylated form of the same antibody used in the coating $(0.5 \mu \mathrm{g} / \mathrm{ml})$. Biotin was detected using a polymeric streptavidin-horseradish peroxidase conjugate (diluted 1:5,000; Sigma-Aldrich), and the ELISA finally developed using a chromogenic peroxidase substrate (Ultra-TMP; Pierce). All samples were run in triplicate, and the concentration of mouse ${ }^{\mathrm{S}} \mathrm{uPAR}$ was calculated using a standard curve generated using known quantities of a purified flag-tagged murine ${ }^{\mathrm{s}} \mathrm{uPAR}$ produced in $\mathrm{CHO}$ cells (13). BM extracellular fluid (BM plasma) from mice was obtained as described previously (28). Briefly, femurs were flushed with PBS; after centrifugation, the supernatant was collected and frozen for analysis. Protein extraction on BMCs was performed as described previously (59). Total protein amounts were determined with the BCA protein analysis kit (Perbio).

Protease activity measurements. BMCs and plasma were collected from WT mice in steady state and at different time points after 5-FU or G-CSF treatment. To quantify plasmin activity, we plated out freshly isolated BMCs in the presence of BM plasma $(50 \% \mathrm{v} / \mathrm{v})$ and added the colorimetric plasmin substrate S-2403 (Chromogenix) in the absence or presence of the plasmin inhibitor trasylol. Plasmin activity $\left(\mathrm{mOD}_{405 \mathrm{~nm}}\right.$, expressed as $\left.\mathrm{AU} / \mathrm{ml}\right)$, was calculated as $\mathrm{OD}_{\text {without trasylol }}-\mathrm{OD}_{\text {with trasylol. }}$. We used BMCs obtained from $\mathrm{Plg}^{-1}$ - mice as negative controls.

In vitro cleavage experiments. For studying in vitro cleavage of $\mathrm{M}_{\mathrm{uPAR}}$, we used human breast adenocarcinoma MDA-MB-231 cells, known to express $\mathrm{M}_{\mathrm{uPAR}}(60)$. Cells were seeded at $2.5 \times 10^{5}$ cells/well in a 48 -well plate, allowed to adhere, and starved overnight in serum-free medium. Thereafter, cells were stimulated with human active plasmin $(1 \mathrm{nM})$, diluted in serum-free medium, and incubated at $37^{\circ} \mathrm{C}$ for 5 hours. This protocol yielded reproducible plasmin activity (assayed by S-2403; Chromogenix) without affecting cellular viability (data not shown). Levels of uPAR in cell lysates and conditioned medium were quantified using commercially available ELISAs (R\&D Systems).

Statistics. We used SPSS software (version 11.0) for statistical calculations. Unless stated otherwise, data (mean \pm SEM) were statistically analyzed by an unpaired, 2-tailed Student's $t$ test. To determine the differences in wbc counts after 5-FU treatment, ANOVA for repeated measurements was used, complemented with 2-tailed Student's $t$ test to identify statistically significant differences at each individual time point. Cox regression was used to analyze the genotypic differences in survival. A $P$ value less than 0.05 was considered statistically significant.

\section{Acknowledgments}

The authors thank A. Carton, L. Cosemans, L. Frederix, E. Gils, L. Godde, B. Hermans, K. Imbrechts, A. Manderveld, K. Maris, W. Martens, S. Meynen, L. Notebaert, J. Souffreau, S. Terclavers, B. Van Hoef, P. Van Wesemael, B. Vanwetswinkel, and S. Wyns (Katholieke Universiteit Leuven) for assistance; W. Landuyt, H. Geeraerts, and E. Devos (Radiobiology, Katholieke Universiteit Leuven) for help with irradiation; and D. Piccini, M. Aliprandi, M. Cinquanta, and $\mathrm{N}$. Venuto (IFOM) for their contribution in the generation of antibodies. We also thank R. Lijnen (Katholieke Universiteit Leu- 
ven), E. Chavakis, and G. Carmona (Goethe University, Frankfurt, Germany) for advice. This work was supported by grants from the European Union (FP6 Contracts no. 502935 and 503297) to F. Blasi; by the Italian Association for Cancer Research (AIRC) to F. Blasi and N. Sidenius; and by the Fund for Scientific Research - Flanders (FWO G.0121.02 and G.0209.07), the Belgian Science Policy (project no. IAP-P5/02), Methusalem Funding, and an unrestricted Bristol-Myers-Squibb grant to P. Carmeliet. M. Tjwa was a research fellow of the Flanders Institute for the Promotion of Innovation by Science and Technology (IWT) and now of the Fund for Scientific Research - Flanders (FWO).

1. McCulloch, E.A., Siminovitch, L., and Till, J.E. 1964. Spleen-colony formation in anemic mice of genotype Ww. Science. 144:844-846.

2. Papayannopoulou, T., Priestley, G.V., and Nakamoto, B. 1998. Anti-VLA4/VCAM-1-induced mobilization requires cooperative signaling through the $\mathrm{kit} / \mathrm{mkit}$ ligand pathway. Blood. 91:2231-2239.

3. Czechowicz, A., Kraft, D., Weissman, I.L., and Bhattacharya, D. 2007. Efficient transplantation via antibody-based clearance of hematopoietic stem cell niches. Science. 318:1296-1299.

4. Heissig, B., et al. 2002. Recruitment of stem and progenitor cells from the bone marrow niche requires MMP-9 mediated release of kit-ligand. Cell. 109:625-637.

5. Driessen, R.L., Johnston, H.M., and Nilsson, S.K. 2003. Membrane-bound stem cell factor is a key regulator in the initial lodgment of stem cells within the endosteal marrow region. Exp. Hematol. 31:1284-1291.

6. Stanford, W.L., et al. 1997. Altered proliferative response by $\mathrm{T}$ lymphocytes of Ly-6A (Sca-1) null mice. J. Exp. Med. 186:705-717.

7. Ito, C.Y., Li, C.Y., Bernstein, A., Dick, J.E., and Stanford, W.L. 2003. Hematopoietic stem cell and progenitor defects in Sca-1/Ly-6A-null mice. Blood. 101:517-523.

8. Bradfute, S.B., Graubert, T.A., and Goodell, M.A. 2005. Roles of Sca-1 in hematopoietic stem/progenitor cell function. Exp. Hematol. 33:836-843.

9. Suzuki, A., et al. 1996. CD34-deficient mice have reduced eosinophil accumulation after allergen exposure and show a novel crossreactive $90-\mathrm{kD}$ protein. Blood. 87:3550-3562.

10. Kiel, M.J., Yilmaz, O.H., Iwashita, T., Terhorst, C., and Morrison, S.J. 2005. SLAM family receptors distinguish hematopoietic stem and progenitor cells and reveal endothelial niches for stem cells. Cell. 121:1109-1121.

11. Balazs, A.B., Fabian, A.J., Esmon, C.T., and Mulligan, R.C. 2006. Endothelial protein C receptor (CD201) explicitly identifies hematopoietic stem cells in murine bone marrow. Blood. 107:2317-2321.

12. Blasi, F., and Carmeliet, P. 2002. uPAR: a versatile signalling orchestrator. Nat. Rev. Mol. Cell Biol. 3:932-943.

13. Andolfo, A., et al. 2002. Metalloproteases cleave the urokinase-type plasminogen activator receptor in the D1-D2 linker region and expose epitopes not present in the intact soluble receptor. Thromb. Haemost. 88:298-306.

14. Beaufort, N., et al. 2004. Plasmin cleaves the juxtamembrane domain and releases truncated species of the urokinase receptor (CD87) from human bronchial epithelial cells. FEBS Lett. 574:89-94.

15. Furlan, F., et al. 2004. The soluble D2D388-274 fragment of the urokinase receptor inhibits monocyte chemotaxis and integrin-dependent cell adhesion. J. Cell Sci. 117:2909-2916.

16. Tarui, T., Mazar, A.P., Cines, D.B., and Takada, Y. 2001. Urokinase-type plasminogen activator receptor (CD87) is a ligand for integrins and mediates cell-cell interaction. J. Biol. Chem. 276:3983-3990.
Received for publication April 23, 2008, and accepted in revised form January 14, 2009.

Address correspondence to: Peter Carmeliet, Vesalius Research Center, VIB, Katholieke Universiteit Leuven, Campus Gasthuisberg, Herestraat 49, Box 912, B-3000, Leuven, Belgium. Phone: 32-16-34-5772; Fax: 32-16-34-59-90; E-mail: peter.carmeliet@med.kuleuven.be.

Marc Tjwa's present address is: Leibniz AG, Centre for Molecular Medicine, Institute of Cardiovascular Regeneration, University of Frankfurt, Frankfurt, Germany.
17. Resnati, M., et al. 1996. Proteolytic cleavage of the urokinase receptor substitutes for the agonistinduced chemotactic effect. EMBO J. 15:1572-1582.

18. Resnati, M., et al. 2002. The fibrinolytic receptor for urokinase activates the $\mathrm{G}$ protein-coupled chemotactic receptor FPRL1/LXA4R. Proc. Natl. Acad. Sci. U. S. A. 99:1359-1364.

19. Selleri, C., et al. 2005. Involvement of the Urokinasetype plasminogen activator receptor in hematopoietic stem cell mobilization. Blood. 105:2198-2205.

20. Selleri, C., et al. 2006. In vivo activity of the cleaved form of soluble urokinase receptor: a new hematopoietic stem/progenitor cell mobilizer. Cancer Res. 66:10885-10890.

21. Fietz, T., Hattori, K., Thiel, E., and Heissig, B. 2006. Increased soluble urokinase plasminogen activator receptor (suPAR) serum levels after granulocyte colony-stimulating factor treatment do not predict successful progenitor cell mobilization in vivo. Blood. 107:3408-3409.

22. Arai, F., et al. 2004. Tie2/angiopoietin-1 signaling regulates hematopoietic stem cell quiescence in the bone marrow niche. Cell. 118:149-161.

23. Wilson, A., et al. 2004. c-Myc controls the balance between hematopoietic stem cell self-renewal and differentiation. Genes Dev. 18:2747-2763.

24. Bonig, H., Priestley, G.V., and Papayannopoulou, T. 2006. Hierarchy of molecular-pathway usage in bone marrow homing and its shift by cytokines. Blood. 107:79-86.

25. Papayannopoulou, T., Craddock, C., Nakamoto, B., Priestley, G.V., and Wolf, N.S. 1995. The VLA4/ VCAM-1 adhesion pathway defines contrasting mechanisms of lodgement of transplanted murine hemopoietic progenitors between bone marrow and spleen. Proc. Natl. Acad. Sci. U. S. A. 92:9647-9651.

26. Scott, L.M., Priestley, G.V., and Papayannopoulou, T. 2003. Deletion of alpha 4 integrins from adult hematopoietic cells reveals roles in homeostasis, regeneration, and homing. Mol. Cell. Biol. 23:9349-9360.

27. Papayannopoulou, T. 2004. Current mechanistic scenarios in hematopoietic stem/progenitor cell mobilization. Blood. 103:1580-1585.

28. Petit, I., et al. 2002. G-CSF induces stem cell mobilization by decreasing bone marrow SDF- 1 and upregulating CXCR4. Nat. Immunol. 3:687-694.

29. Tjwa, M., et al. 2008. Fibrinolysis-independent role of plasmin and its activators in the hematopoietic recovery after myeloablation. J. Cell. Mol. Med. Online publication ahead of print. doi:10.1111/ j.1582-4934.2008.00521.x.

30. Ploplis, V.A., et al. 1995. Effects of disruption of the plasminogen gene on thrombosis, growth, and health in mice. Circulation. 92:2585-2593.

31. Randall, T.D., and Weissman, I.L. 1997. Phenotypic and functional changes induced at the clonal level in hematopoietic stem cells after 5-fluorouracil treatment. Blood. 89:3596-3606.

32. Hurley, R.W., McCarthy, J.B., and Verfaillie, C.M. 1995. Direct adhesion to bone marrow stroma via fibronectin receptors inhibits hematopoietic progenitor proliferation. J. Clin. Invest. 96:511-519.

33. Prosper, F., Stroncek, D., McCarthy, J.B., and Ver- faillie, C.M. 1998. Mobilization and homing of peripheral blood progenitors is related to reversible downregulation of alpha4 beta 1 integrin expression and function. J. Clin. Invest. 101:2456-2467.

34. Montuori, N., Carriero, M.V., Salzano, S., Rossi, G., and Ragno, P. 2002. The cleavage of the urokinase receptor regulates its multiple functions. J. Biol. Chem. 277:46932-46939.

35. Rosu-Myles, M., et al. 2000. The human hematopoietic stem cell compartment is heterogeneous for CXCR4 expression. Proc. Natl. Acad. Sci.U. S. A. 97:14626-14631.

36. Orschell-Traycoff, C.M., et al. 2000. Homing and engraftment potential of Sca-1(+)lin(-) cells fractionated on the basis of adhesion molecule expression and position in cell cycle. Blood. 96:1380-1387.

37. Desponts, C., Hazen, A.L., Paraiso, K.H., and Kerr, W.G. 2006. SHIP deficiency enhances HSC proliferation and survival but compromises homing and repopulation. Blood. 107:4338-4345.

38. Harrison, D.E. 1980. Competitive repopulation: a new assay for long-term stem cell functional capacity. Blood. 55:77-81.

39. Priestley, G.V., Scott, L.M., Ulyanova, T., and Papayannopoulou, T. 2006. Lack of alpha4 integrin expression in stem cells restricts competitive function and self-renewal activity. Blood. 107:2959-2967.

40. Papayannopoulou, T., Priestley, G.V., Nakamoto, B., Zafiropoulos, V., and Scott, L.M. 2001. Molecular pathways in bone marrow homing: dominant role of alpha(4)beta(1) over beta(2)-integrins and selectins. Blood. 98:2403-2411.

41. Foudi, A., et al. 2006. Reduced retention of radioprotective hematopoietic cells within the bone marrow microenvironment in CXCR4 $4^{-/}$chimeric mice. Blood. 107:2243-2251.

42. Levesque, J.P., Hendy, J., Winkler, I.G., Takamatsu, Y., and Simmons, P.J. 2003. Granulocyte colonystimulating factor induces the release in the bone marrow of proteases that cleave c-KIT receptor (CD117) from the surface of hematopoietic progenitor cells. Exp. Hematol. 31:109-117.

43. Nakamura, Y., et al. 2004. Soluble c-kit receptor mobilizes hematopoietic stem cells to peripheral blood in mice. Exp. Hematol. 32:390-396.

44. Heissig, B., et al. 2007. The plasminogen fibrinolytic pathway is required for hematopoietic regeneration. Cell Stem Cell. 1:658-670.

45. Eagleson, K.L., Bonnin, A., and Levitt, P. 2005. Region- and age-specific deficits in gamma-aminobutyric acidergic neuron development in the telencephalon of the uPAR(-/-) mouse. J. Comp. Neurol. 489:449-466.

46. Katayama, Y., et al. 2003. PSGL-1 participates in E-selectin-mediated progenitor homing to bone marrow: evidence for cooperation between E-selectin ligands and alpha4 integrin. Blood. 102:2060-2067.

47. Mazzieri, R., et al. 2007. A direct link between expression of urokinase plasminogen activator receptor, growth rate and oncogenic transformation in mouse embryonic fibroblasts. Oncogene. 26:725-732.

48. Jetmore, A., et al. 2002. Homing efficiency, cell 
cycle kinetics, and survival of quiescent and cycling human CD34(+) cells transplanted into conditioned NOD/SCID recipients. Blood. 99:1585-1593.

49. Vermeulen, M., et al. 1998. Role of adhesion molecules in the homing and mobilization of murine hematopoietic stem and progenitor cells. Blood. 92:894-900.

50. Mustjoki, S., et al. 2000. Soluble urokinase receptor levels correlate with number of circulating tumor cells in acute myeloid leukemia and decrease rapidly during chemotherapy. Cancer Res. 60:7126-7132.

51. Jamieson, C.H., et al. 2004. Granulocyte-macrophage progenitors as candidate leukemic stem cells in blast-crisis CML. N. Engl. J. Med. 351:657-667.

52. Tjwa, M., Janssens, S., and Carmeliet, P. 2008. Plasmin therapy enhances mobilization of HPCs after G-CSF. Blood. 112:4048-4050.
53. Dewerchin, M., et al. 1996. Generation and characterization of urokinase receptor-deficient mice. J. Clin. Invest. 97:870-878.

54. Hattori, N., et al. 2000. Bleomycin-induced pulmonary fibrosis in fibrinogen-null mice. J. Clin. Invest. 106:1341-1350.

55. Frenette, P.S., Subbarao, S., Mazo, I.B., von Andrian, U.H., and Wagner, D.D. 1998. Endothelial selectins and vascular cell adhesion molecule-1 promote hematopoietic progenitor homing to bone marrow. Proc. Natl. Acad. Sci. U. S. A. 95:14423-14428.

56. Passegue, E., Wagers, A.J., Giuriato, S., Anderson, W.C., and Weissman, I.L. 2005. Global analysis of proliferation and cell cycle gene expression in the regulation of hematopoietic stem and progenitor cell fates. J. Exp. Med. 202:1599-1611.

57. Inoue, A., et al. 2002. Slug, a highly conserved zinc finger transcriptional repressor, protects hematopoietic progenitor cells from radiation-induced apoptosis in vivo. Cancer Cell. 2:279-288.

58. Kristensen, P., Eriksen, J., Blasi, F., and Dano, K. 1991. Two alternatively spliced mouse urokinase receptor mRNAs with different histological localization in the gastrointestinal tract. J. Cell Biol. 115:1763-1771.

59. Heymans, S., et al. 1999. Inhibition of plasminogen activators or matrix metalloproteinases prevents cardiac rupture but impairs therapeutic angiogenesis and causes cardiac failure. Nat. Med. 5:1135-1142.

60. Holst-Hansen, C., et al. 1996. Urokinase-type plasminogen activation in three human breast cancer cell lines correlates with their in vitro invasiveness. Clin. Exp. Metastasis. 14:297-307. 